\title{
Electrical hubs: an effective way to integrate non-dispatchable renewable energy sources with minimum impact to the grid
}

\author{
A.T.D. Perera ${ }^{\mathrm{a}, \mathrm{b} 1}$, Vahid M. Nik ${ }^{\mathrm{c}}$, Dasaraden Mauree ${ }^{\mathrm{a}}$, Jean-Louis Scartezzini ${ }^{\mathrm{a}}$
}

${ }^{a}$ Solar Energy and Building Physics Laboratory (LESO-PB), Ecole Polytechnique Fédérale de Lausanne (EPFL), CH-1015 Lausanne, Switzerland.

${ }^{\mathrm{b}}$ Department of Mechanical Engineering, University of Moratuwa, 10400, Katubedda, Sri Lanka.

${ }^{c}$ Division of Building Physics, Department of Building and Environmental Technology, Lund University, Lund, Sweden.

\section{Abstract}

A paradigm change in energy system design tools, energy market, and energy policy is required to attain the target levels in renewable energy integration and in minimizing pollutant emissions in power generation. Integrating nondispatchable renewable energy sources such as solar and wind energy is vital in this context. Distributed generation has been identified as a promising method to integrate Solar PV (SPV) and wind energy into grid in recent literature. Distributed generation using grid-tied electrical hubs, which consist of Internal Combustion Generator (ICG), nondispatchable energy sources (i.e., wind turbines and SPV panels) and energy storage for providing the electricity demand in Sri Lanka is considered in this study. A novel dispatch strategy is introduced to address the limitations in the existing methods in optimizing grid-integrated electrical hubs considering real time pricing of the electricity grid and curtailments in grid integration. Multi-objective optimization is conducted for the system design considering grid integration level and Levelized Energy Cost (LEC) as objective functions to evaluate the potential of electrical hubs to integrate SPV and wind energy. The sensitivity of grid curtailments, energy market, price of wind turbines and SPV panels on Pareto front is evaluated subsequently. Results from the Pareto analysis demonstrate the potential of electrical hubs to cover more than $60 \%$ of the annual electricity demand from SPV and wind energy considering stringent grid curtailments. Such a share from SPV and wind energy is quite significant when compared to direct grid integration of non-dispatchable renewable energy technologies.

Key words: Distributed generation, grid integration, electrical hubs, multi-objective optimization, non-dispatchable energy

\footnotetext{
${ }^{1}$ Corresponding Author

Email:dasun.perera@epfl.ch,

Tel: +41 2169 35746, Fax: +41216932722
} 


\section{Introduction}

29 Integrating renewable energy technologies into the electricity grid is gradually getting popular due to rapid depletion of fossil fuel resources and global concerns on greenhouse gases emissions and nuclear energy. Several countries

31 have their own goals with different time lines in this regard. For example, Germany has a goal to cover $50 \%$ of the

32 generation system using renewable energy by 2030 [1], while in Finland it is $38 \%$ by 2020 [2]. Switzerland is expected to phase-out nuclear energy by 2035 by increasing the energy efficiency and the share of renewable energy sources. In Sri Lanka, it is expected to increase the share of non-conventional renewables, such as SPV and wind energy, up to $20 \%$ by the end of 2020 . Recent studies highlight that distributed generation using solar PV (SPV) and wind energy is promising to foster the renewable energy penetration in the market [3], [4].

Energy systems fully driven using renewable energy sources is a dream that wider community of researchers try to make a reality [5]-[9]. Replacing dispatchable energy sources driven by fossil fuel through distributed SPV, wind and biomass/bio energy sources is the major challenge in this context. Mismatch in time of peak demand and generation due to stochastic nature of wind speed and solar radiation as well as of electricity demand makes the renewable energy integration process difficult [10], [11]. Integration of dispatchable energy sources, energy storage and converting into hybrid renewable energy systems is a cost effective approach in increasing the reliability during the renewable energy integration process. Further, this helps to amalgamate energy sources with higher seasonal variation in energy potential [12], [13] with less impact to the grid. More importantly, this is the starting point of minimizing the contribution of dispatchable energy sources based on fossil fuels, which makes existing energy systems more eco-friendly and sustainable [10], [14]. However, optimum designing of such energy systems is a challenging task.

Several research groups have focused on optimizing grid-integrated hybrid energy systems which Fathima and Palanisamy [15] provide a review of the major recent works. Two different approaches can be used in this context to optimize the system design and dispatch simultaneous.

1) Energy system is expected to operate in finite set of states (finite state machines) in which operating conditions for the dispatchable energy sources and storage is defined. Subsequently, state transfer function is optimized along with the energy system (sizing problem) based on the objective functions considered [16]-[19]. 
2) Optimum operating conditions for dispatchable energy sources and storage is obtained for each time step considering these as decision space variables [20]-[24]. This can be further classified into two groups, depending whether dispatching is optimized as time depended small scale problems or globally as a unique large size problem as explained in Ref. [25].

Both these methods are coming with their strengths and weaknesses. The first method can consider non-linear models (considering valve point effect etc) easily for energy conversion processes without simplification and present performance of the system (for 8760 time steps) with less computational time. However, the number of possible states that the system could operate increases exponentially with the complexity of the energy flow within the system (especially for poly-generation with multiple dispatchable energy sources and storages). Second method is more suitable when considering complex energy systems with multiple dispatchable sources and storage. However, computational time and the resources required become extremely high when using this method. According to Evins [22] optimization time can reach up to seven days when considering second method while Pruitt et al [24] report that there are limitations in handling a time horizon due to the increase of decision space variables. Further, simple linearization of objective functions can influence the results of the optimization problem significantly [26]. Hence, designing energy systems with simple energy flow such as hybrid energy systems and grid tied hybrid energy systems tends to use the first method while the second method is used for ploy-generation [20]-[24].

The first part of the manuscript introduces a novel optimization algorithm to design grid integrated electrical hubs extending the first method based on finite states. Electrical hub is a simplified version of multi-energy hubs (amply studied in recent literature considering its operation [27]-[31] and design optimization [22]). The electrical hub consists of wind turbines, SPV panels, battery bank and an Internal Combustion Generator (ICG) which is designed to operate as a grid-tied hybrid energy system. Finite state machines have been amply used to optimize energy systems with similar architecture to electrical hubs and hybrid energy systems which are operating both stand alone and grid integrated modes [18], [19], [32]-[35] (including previous works of the authors [17], [36]). In previous studies of the authors, [17], [36], multi objective optimization and multi criterion decision making related to standalone hybrid energy systems were taken into discussion without any grid interactions. A comprehensive review about optimization techniques used on this regard can be found in Ref. [37]. Grid integrated hybrid energy with a similar architecture to electrical hubs have been also optimized by extending the dispatch strategy used to optimize stand-alone systems [38], [39]. As a result, the state of the charge of the battery bank and the price of electricity in 
the grid has not been considered in the dispatch strategy although these factors can significantly influence the cash flow of the system according to Ref. [40], [41]. Number of states that system could operates increase notably when considering the energy storage, dispatchable energy sources and grid interactions simultaneously. In order to address this issue, this study introduces a novel bi-level dispatch strategy coupling fuzzy logic and finite state machines in order to optimize system design along with dispatch strategy. Fuzzy logic has been amply used in dispatch optimization of hybrid energy systems [42]-[45] which is considered as one of the most promising techniques by the recent review on energy management strategies for hybrid energy systems [46]. However, for the best of author's knowledge fuzzy logic has not been used for dispatching to support design optimization (system sizing) before, which can be used as an attractive method to address the limitations in the existing design optimization process.

The second part of the manuscript presents a detailed assessment on the potential of electrical hubs to integrate SPV and wind energy with a minimum impact to the grid (making the energy system to be autonomous while minimize the energy export and import to and from the grid). Integrating higher fractions of non-dispatchable renewable energy technologies while operating at higher autonomy levels (minimum grid interactions) is a difficult task [47], [48]. According to Ueckerd et-al [49] direct integration of higher fractions of non-dispatchable renewable energy sources above $30 \%$ is beyond the reach due to the limitations in the grid. A quantitative and qualitative analysis about the potential of integrated energy systems (such as electrical hubs) to extend the SPV and wind energy integration (with minimum impact to the grid) is missing in literature besides its timely importance. This moves beyond design optimization where detailed assessment of the electrical hub is required. To achieve this objective, Pareto optimization is conducted in this study considering Levelized Energy Cost (LEC) and Grid Interaction (GI) level (extending the definitions in Ref. [47], [48] ) as objective functions. Decision space variables related to the system sizing problem and variables of the dispatch strategy are considered as decision space variables to be optimized. Sensitivity of the mode of grid interactions (importing and exporting electricity from the grid), the price of electricity and the curtailments in the grid and role of ICG and energy storage on SPV and wind energy integration are taken as the aspects to be assessed.

The manuscript is arranged in the following manner; a novel method to optimize electrical hubs is proposed in the first part of the manuscript extending existing methods to optimize grid integrated hybrid energy systems. The second part is devoted to evaluate the potential of electrical hubs to increase the SPV and wind energy contribution with a minimum impact to the electricity distribution grid considering the recent and future changes in the grid. 


\section{Overview of the problem}

112 This section provides an overview about the concept of electrical hub within the framework of distributed generation

113 under section 2.1 and system configuration considered for the electrical hub in Section 2.2. A detailed overview

114 about the novel computational model developed to design electrical hubs is also taken into discussion in this section

115 (2.3) mapping it into different parts of the manuscript. Main parts of the computational model and interconnection

116 among components is illustrated in Section 2.3.

$117 \quad 2.1)$ Distributed generation to electrical hubs

118 It is a challenging task to use distributed renewable energy sources in order to deliver the distributed demand. This 119 needs to be achieved through several steps as demonstrated in Fig. 1. Distributed demand should be identified: 120 building performance simulation tools such as EnergyPlus [50] or CitySim [51] can be used to calculate the

121 distributed demand. Clustering the demand helps to locate "demand centers" where the distributed energy systems

122 will be located [52]. Hence, clustering the distributed demand is followed by building energy modeling as shown in

123 Fig. 2. Simultaneously, it is important to assess the potential of renewable energy sources being parallel to the

124 demand simulation. This is usually achieved in two steps. First, energy maps are used to identify the promising renewable energy technologies (qualitatively). Afterwards, a detailed analysis (quantitatively) is conducted to gather the basic time series data for the selected energy technologies (which were identified as promising energy

127 technologies during the first step).

Designing distributed energy systems consists of two processes i.e., designing the energy systems and designing the grid. This study only focuses on the energy system, therefore operation and maintenance of the utility grid is not considered. The method which is introduced in this study can be used to assess the potential of renewable energy

131 integration in virtual power plants, smart micro-grids, grid-tied hybrid energy systems with minor modifications in 132 boundary conditions, and the computational model [53]-[55] which are similar in operation.

\section{2) System configuration of the electrical hub}

134 The Electrical hub, considered in this paper consists of two non-dispatchable energy sources: solar PV panels and wind turbines, as well as one dispatchable energy source; an Internal Combustion Generator (ICG) (Fig. 2). Moreover, a battery bank is used as the energy storage. The battery bank is used to absorb the fluctuations of renewable energy generation and demand of the electrical hub. As shown in Fig. 2, the electrical hub interacts with 

curtailments are considered for both import and export electricity to and from the electrical hub and real time price is

140 considered from the Energy Service Provider when interacting with the grid which differentiate the present study

141 from a simple grid connected hybrid energy systems. The electrical hub responds to the price signals of the grid when determining the operation strategy.

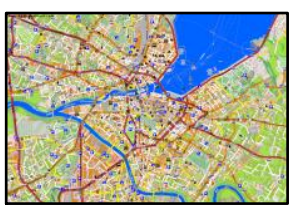

Collecting basic data
Boundary of the electrical hub considered

- Distributed demand

Energy System

Main Utility Grid

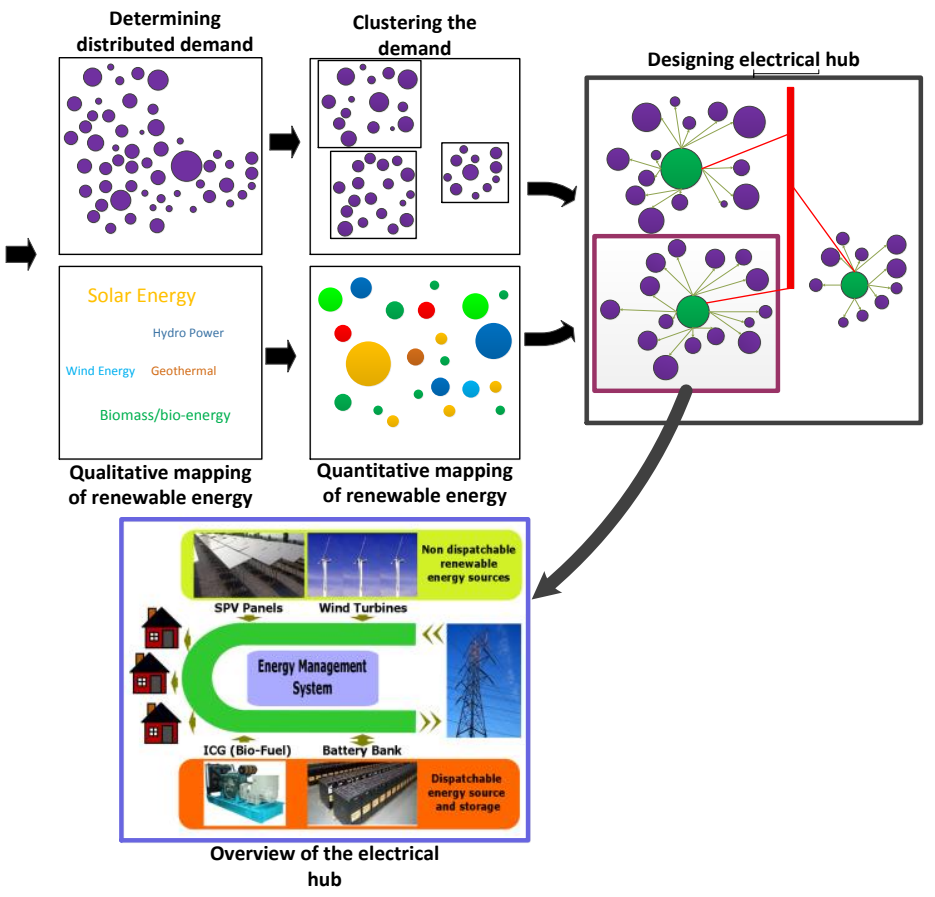

Fig. 1 Overview of the design problem

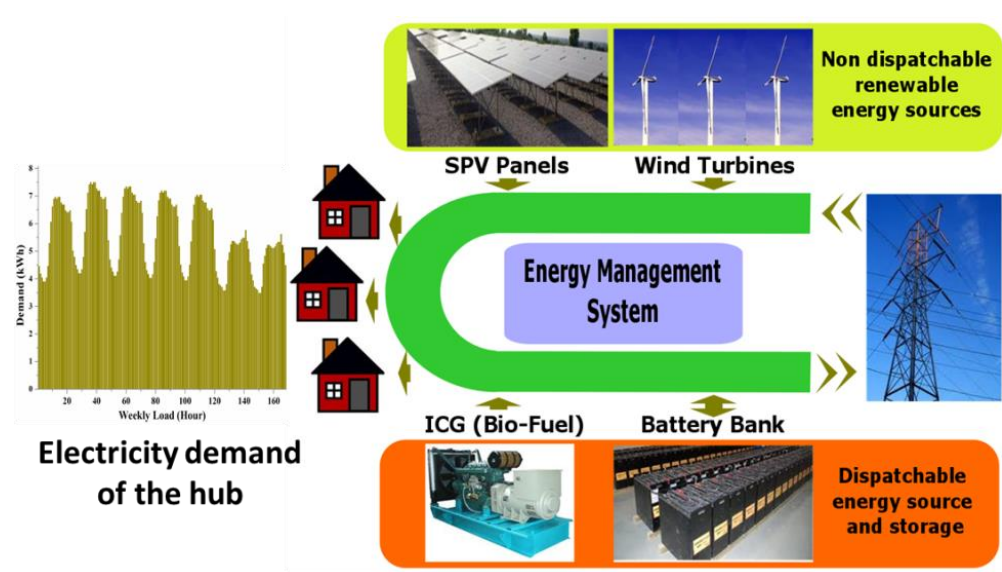

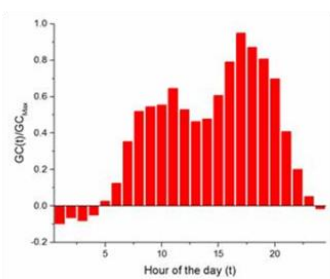

Real time price by ESP 


\section{3) Overview of the developed design tool}

148 Design optimization of electrical hubs consists of several interconnected steps. Energy System design process starts

149 with collecting basic techno-economic data, renewable energy potentials, demand profile and information related to the grid. Main objective of the computational model is to optimize the design and control strategy based on the objective functions considered. Variables related to the system configuration (capacity of wind turbines, SPV panels, battery bank, ICG and the type of wind turbine and SPV panels used for the design) and dispatch strategy are considered as the decision space variables in the optimization algorithm. Levelized Energy Cost (LEC) and Grid Integration (GI) level are considered as objective functions and power supply reliability and grid curtailments are

Fig.3.

157

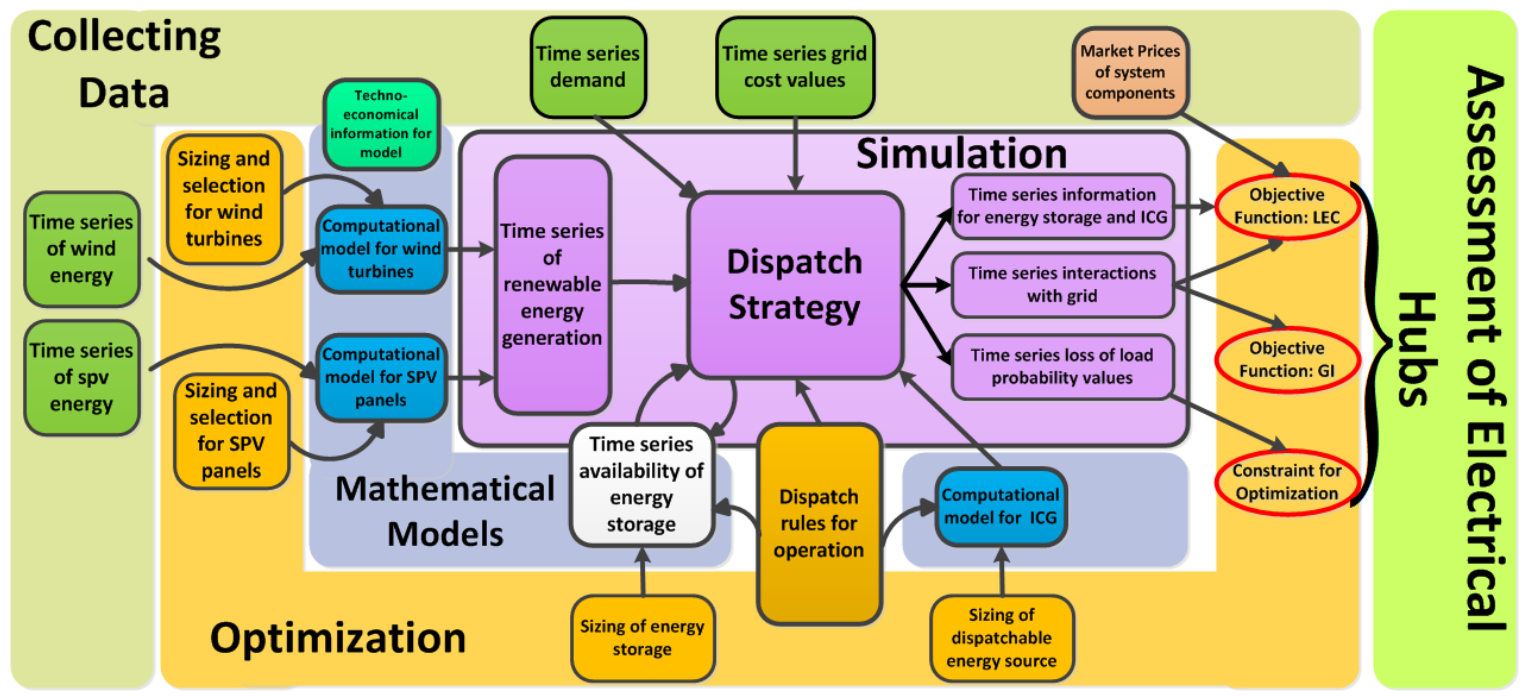

Fig. 3 Outlook of the computational tool

The first part of the computational model is used to calculate the energy generation of renewable energy technologies (SPV panels and wind turbines) as shown in Fig. 3. A mathematical model is developed to present the energy conversion process in each system component towards achieving this objective. The task of the simulation block is to compute performance indicators that are used to formulate objective functions being connected to the mathematical models. In order to achieve this, energy flow (energy conversion through the path) of the system is evaluated considering the hourly time series of the renewable power generation, demand and electricity price in the 
grid. Time series simulation is amply used in energy system optimization in order to evaluate the performance of the system throughout the year[16], [17], [22].

Sizing and selection of the system components affect the energy flow considerably and need to be considered in modelling. This makes the optimization block to be sandwiched between two blocks (i.e. Collecting Data and Mathematical Model). Mathematical model will present the energy conversion process of each system device. Computational model for wind turbines and SPV panels will generate a time series of hourly power generated using the computational model which is transferred to the Simulation block as shown in Fig. 3. Similarly, mathematical models for energy storage and ICG are used in evaluating the energy flow being coupled with the dispatch strategy. An extended explanation about each block is provided in sections 3, 4 and 5.

\section{Mathematical model for the electrical hub}

The mathematical model developed in this work consists of several parts devoted to analyze the energy and cash flow of the system, grid interactions and power supply reliability. This is used to formulate LEC and Grid Integration (GI) level which are considered as objective functions (F€F: set of objective functions) to be optimized Power supply reliability is considered as a constraint as defined in Section 3.3. Decision space represents variables of the system design and operation (dispatch strategy); the system design variables consist of the type (technology) of SPV panels, wind turbines and the capacities of SPV panels, wind turbines, ICG and battery bank in the optimum system design ( $\mathrm{N} \epsilon \mathrm{N}$ : set of decision space variables related to system design). This section formulates the time series of renewable power generation using SPV and wind based on the corresponding values of the decision space variables.

\subsection{Energy flow model}

The main objective of the energy flow model is to evaluate the power generation and energy conversion processes within the system as discussed in Section 2.3. A brief description of the computational model which is used to determine the electricity generation through the dispatchable/non-dispatchable sources and the other energy conversion processes is presented in this section. 


\subsubsection{Modeling non-dispatchable energy technologies}

192 Time series of hourly solar radiation on a horizontal plane for the considered location are obtained from the closest

193 meteorological station. These values are used to calculate the solar radiation on a tilted plane that comprises the SPV panels (e.g. $\mathrm{G}_{\mathrm{t}}^{\beta}$ ) using an anisotropic diffuse solar radiation model. A detail description of the corresponding model is given in Ref. [56]. Thereafter, a semi empirical formula proposed by Durisch et al. [26] is used to determine the energy efficiency of the SPV panels $\eta_{t}^{S P V}$ for time step $t(t \in T$ : set of all hoursinthe year) according to $\mathrm{Eq} 1$.

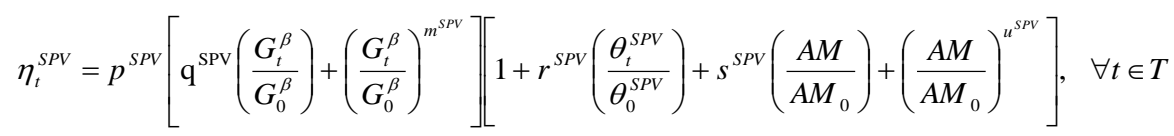

In Eq. $1, \mathrm{AM}$ is the air mass value [27] and $\theta_{t}^{S P V}$ is the solar cell temperature. Standard values for $G_{0}^{\beta}, \theta_{0}^{S P V}, A M_{0}$ are taken respectively as $G_{0}^{\beta}=1000 \mathrm{Wm}^{-2}, \theta_{0}^{S P V}=25^{\circ} \mathrm{C}$ and $A M_{0}=1.5$. Parameter values of $p^{S P V}, \mathrm{q}^{\mathrm{SPV}}, r^{S P V}$, $s^{S P V}, m^{S P V}, u^{S P V}$ for different SPV technologies, such as mono-crystalline, polycrystalline and amorphous silicon cells, are taken from Ref. [57]. The hourly power supply from the SPV panels $P_{t}^{S P V}$ is calculated according to Eq. 2. $A^{S P V}$ and $N^{S P V}\left(N^{S P V} \in \mathrm{N}\right)$ represent the area of a single SPV panel as well as the number of SPV panels.

$P_{t}^{S P V}=G_{t}^{\beta} \eta_{t}^{S P V} A^{S P V} N^{S P V}, \forall t \in T$

Similar to the energy conversion model of the SPV panels, the energy flow model for wind turbines consist of two main components: i) a model to evaluate the wind speed at the hub level of the wind turbine and ii) a model to evaluate the electrical power generation from wind turbines. Hourly wind speed at $10 \mathrm{~m}$ anemometer height is used to calculate wind speed at hub level $\left(\mathrm{v}_{\mathrm{t}}\right)$ of the wind turbine using a power law approximation.

Performance of the wind turbine can be modelled mainly using two different types of models turbine according to Thapar et al. [58]. These are wind turbine models based on the presumed shape and wind turbine models based actual shape of the performance curve of wind turbine. Thapar et-al [58] shows that the latter is more accurate in many applications. This study is using the second method. In this method, the "power curve" of the wind turbine, provided by the manufacturer is taken and the wind turbine is modeled using $\mathrm{n}_{\mathrm{s}}$ number of cubic spline interpolation functions, considering $\mathrm{n}_{\mathrm{s}}+1$ points from the power curve given by the manufacturer [59], [60] according to Eq. 3 . 


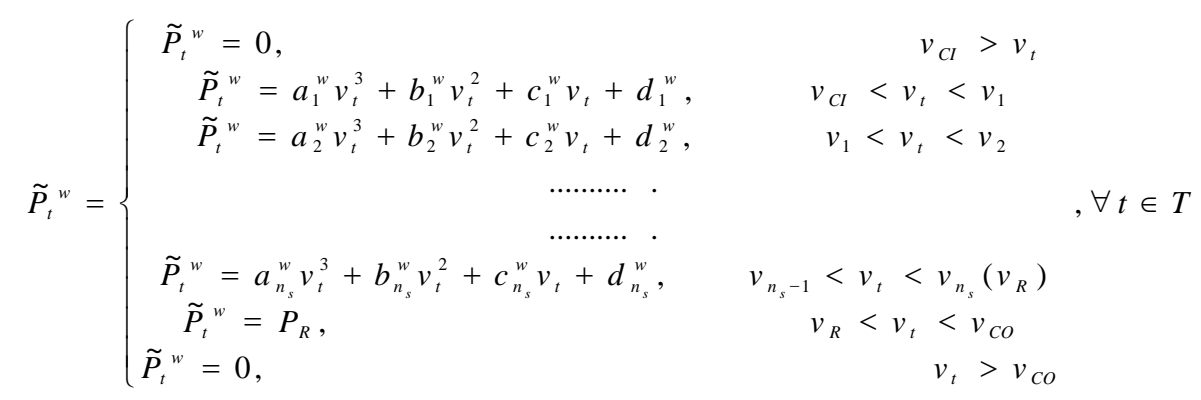

In Eq. 3, $a_{i}^{w}, b_{i}^{w}, c_{i}^{w}$, and $d_{i}^{w}$ are coefficients of the polynomial function which vary depending on the "power curve". $\mathrm{v}_{\mathrm{R}}, \mathrm{v}_{\mathrm{CI}}, \mathrm{v}_{\mathrm{CO}}$ and $\mathrm{P}_{\mathrm{R}}$ denote rated wind speed, cut-in wind speed, cut-off wind speed and rated power of the wind turbine. Finally, net power generation $\left(P_{t}^{W}\right)$ is calculated using Eq. 4.

$$
P_{t}^{W}=\tilde{P_{t}^{W}}\left(\mathrm{v}_{\mathrm{t}}\right) \mathrm{N}^{\mathrm{w}} \eta^{\mathrm{w}-\text { losses }}, \forall t \in T
$$

In Eq. 4, $N^{W}\left(N^{W} \in \mathrm{N}\right)$ denotes the number of wind turbines which is optimized using the optimization algorithm, $\tilde{p_{t}^{W}}$ denotes power generated by one wind turbine calculated using the power curve and $\eta^{\text {w-loses }}$ accounts for other losses that take place in the energy conversion.

\subsubsection{Modeling dispatchable energy technologies}

The battery bank and the Internal Combustion Generator (ICG) are used to store and supply the dispatchable energy requirement. Hourly energy requirement from the dispatchable energy source and storage is determined by the dispatch strategy which is illustrated in detail in Section 4. Fuel consumption of the ICG $\left(F_{t}^{I C G}\right)$ is calculated based on hourly power generation from ICG $\left(P_{t}^{I C G}\right)$ according to Eq. 5. Fuel consumption is usually computed using linear relationship of load factor [61]. A fourth order polynomial function of load factor (based on the performance curve

233 of the ICG provided by the manufacturer) is used to model [35], [61], [62] the fuel consumption in this study in 234 order to improve the accuracy of the calculations. 
In this equation, $a_{k}^{I C G}, b_{k}^{I C G}, c_{k}^{I C G}, d_{k}^{I C G}$ and $e_{k}^{I C G}$ are taken from the performance curve of the $\mathrm{k}^{\text {th }}$ ICG, $k(k \in \mathrm{N})$,

237 obtained from the optimization algorithm. In this equation, $y_{t}$ denotes the operating load factor of ICG which is

238 calculated using fuzzy logic controller according to Section 4.1. Life time of the ICG is considered based on the

239 operating time of the ICG. Based on that, number of replacement for the ICG is calculated which is used for the cost 240 model.

241 State of Charge (SOC) of the battery bank is determined using finite state machines as describes in Section 4.2.

242 Capacity of the battery bank $N^{\text {Bat }}\left(N^{B a t} \epsilon N\right)$ is optimized using the optimization algorithm. Self-discharge rate of the

243 battery bank is taken as $0.02 \%$ of the charge level. The Rain-Flow Algorithm [63] is used to determine the life time

244 of the battery bank depending on the number of charge/discharge cycles. Based on that number of replacement for

245 the battery bank, life cycle cash flow for the energy storage is calculated.

\subsection{Grid interaction level}

The electricity grid is a critical infrastructure which is vulnerable to cascade failures [64]. Strong interactions via both importing and exporting electricity are discouraged from a perspective of grid stability. Stability of the grid is considered in two different steps in the design process of the grid integrated energy system [43]. Firstly, curtailments for grid interactions are introduced. Due to hourly, daily and seasonal changes in both electricity demand and renewable energy supply, it is difficult to determine these parameters which should ideally be dynamic. Hence, grid curtailments are introduced as an upper bound for the energy interactions with the grid in this work. Secondly, a method is used to minimize the net interactions considering either importing or exporting energy from the grid or both. The two methods can be used as a performance indicator to evaluate the autonomy level of the system. It is important to note that these methods cannot replace the technical procedures used to access and monitor the stability and performance of the grid, which need to be carried out after the optimization of the system design.

The maximal limit for grid interaction (both to and from) is limited to $\mathrm{EG}_{\mathrm{Lim}}$ (i.e., the maximal power units that can be sold to the grid within a time step) and $\mathrm{IG}_{\mathrm{Lim}}$ (e.g., the maximal power units that can be purchased from grid within a time step) belonging to the first category. Three different performance indicators are used in this study to measure the interaction with the grid which are developed based on [48], [65]. The first indicator, $\mathrm{GI}_{\mathrm{IG}}$ is based on the total electricity amount purchased from the grid (Eq. 6). This indicator depicts the support of the grid to maintain the reliability level of the electrical hub. The second indicator, $\mathrm{GI}_{\mathrm{EG}}$ is the total energy amount that is sold or 
exported to the grid (Eq. 7). With the integration of renewables, selling electricity to the grid becomes essential in order to minimize the operating cost of the system; though, excess transfer of electricity can reduce the stability of the grid. Finally, energy flows in both directions are considered as the third indicator $\left(\mathrm{GI}_{\mathrm{IEG}}\right)$ as shown in Eq. 8 .

$G I_{\mathrm{IEG}}=\frac{\sum_{\forall t \in T} P_{t}^{E G}+P_{t}^{I G}}{\sum_{\forall t \in T} P_{t}^{E L D}}$

269 In these equations, $P_{t}^{E L D}$ denotes electricity demand of the electrical and $P_{t}^{I G}$ and $P_{t}^{E G}$ denotes the power imported

270 and exported to and from the grid. The formulation for both these parameters depends on operating state. For an 271 example $P_{t}^{E G}$ can be defined according to Eq. 9 for a one simple operating state i.e. State 3 (described in Section

272 4.2) which is different in other operating states.

$P_{t}^{E G}=P_{t}^{R E}+P_{t}^{I C G}-E L D_{t}, \forall t \in T$

274 In this equation, $E L D_{t}$ and $P_{t}^{R E}$ denote electricity load demand of the application and renewable power generation ( $\left.275 P_{t}^{W}+P_{t}^{S P V}\right)$.

\subsection{Power supply reliability of the hub}

278 Power supply reliability is calculated in this study using the loss of load probability (LOLP) model used in Ref.

279 [66]-[69]. Loss of power supply (LPS) is considered to be occurring whenever power generation within the system

280 is less than the demand (according to Eq. 10); and the mismatch cannot be supplied by both battery bank (due to the 281 limitations in energy storage) and grid (due to the grid curtailments).

$$
L P S_{t}=E L D_{t}-P_{t}^{R E}-P_{t}^{I C G}-P_{t}^{B a t-M a x}-I G_{L i m}, \forall t \in T
$$

$283 P_{t}^{\text {Bat-Max }}$ denotes maximum power flow from the battery depending upon the state of charge. 
LOLP presents the probability that loss of power supply can occur due to the limitations in the generation when catering the demand for the time period considered. $\sum_{\forall t \in T} L P S_{t}$ presents the expected loss of energy, or energy not supplied for the time period considered (8760 hours). LOLP presents the LPS as a fraction of total demand according to Eq. 11 which is used as the performance indicator to evaluate the power supply reliability.

$L O L P=\frac{\sum_{\forall t \in T} L P S_{t}}{\sum_{\forall t \in T} P_{t}^{E L D}}$

\subsection{Life Cycle Cost Model}

The developed Life Cycle Cost (LCC) model evaluates the cash flows taking place during different time periods of the project. The cost model consists of three components: i) the Initial Capital Cost (ICC), ii) a Fixed Annual Cashflow (FAC) and iii) Variable Annual Cash-flow (VAC). The ICC of system components comprises the purchase and installation costs for the systems components. The ICC of the whole system is determined considering the initial financial investment of the wind turbines, the SPV panels, the battery bank, the ICG and the power electronic equipment (such as DC/AC converters and inverters).

VAC includes the replacement cost of the battery bank, ICG and inverters, which depends on operating conditions, operating hours and life expectancy. Replacing time for the battery bank is calculated as described in Section 2.1.2. The present value of $\mathrm{VAC}\left(\mathrm{VAC}_{\mathrm{PV}}\right)$ is subsequently calculated. The Net Present Value (NPV) of the system comprises of all the cash flows mentioned above. Finally, NPV is used to calculate Levelized Energy Cost (LEC) considering the ELD of the electrical hub.

\section{Novel dispatch strategy and simulation}

Seasonal variations of the renewable energy potential, demand and the dispatch strategy of the system notably influence the system sizing [70]. Hence, simulation of the system, considering hourly variation of renewable energy potential, grid conditions and demand is vital. Meanwhile, power generation using dispatchable energy sources and energy interactions with storage and grid need to be carried out in an optimum way. This mean that dispatch strategy needs to be optimized with the system simultaneously. A bi-level dispatch strategy is introduced in this section 
which is used in order to achieve this task along with the decision space variables used to optimize dispatch strategy ( $\mathrm{d} \in \mathrm{D}$ : set of decision space variables for system control ). Section 4.1, introduces the primary algorithm based on fuzzy logic and Section 4.2 introduces the secondary algorithm based on finite state machines. Hourly simulation of the system based on the dispatch strategy generates the time series of hourly fuel consumption and SOC which are used to calculate the costs related to ICG and the life time of battery bank, system reliability and the grid integration levels.

\subsection{Primary level dispatch strategy}

The dispatch strategy consists of two main steps as explained in Fig. 4 (marked in blue and green). In the first step, the operating state (load factor) of the ICG $\left(\mathrm{y}_{\mathrm{t}}\right)$ is determined based on two input variables $\mathrm{x}_{\mathrm{t}}{ }^{1}$ and $\mathrm{x}_{\mathrm{t}}{ }^{2}$ representing normalized depth of Discharge (DoD) of the battery bank and the normalized load mismatch between demand and the renewable energy generation (Eq. 12).

$$
x_{t}^{1}=\frac{P_{t}^{E L D}-P_{t}^{R E}}{\max _{\forall t \in T}\left(P_{t}^{E L D}-\left(P_{t}^{S P V}+P_{t}^{w}\right)\right)}
$$

The depth of discharge of the battery bank is calculated in a similar way using the SOC battery bank. Normalized values of DOD are designated by $\mathrm{x}_{\mathrm{t}}^{2}$ similar to Eq. 12 .

Takagi-Sugino method [71]-[73] is used in this study to load factor of the ICG. Fuzzy implication $\mathrm{R}^{1}$ for $\mathrm{t}^{\text {th }}$ fuzzy subspace is defined according to Eq. 13

$R^{1}$ : If $g_{1}\left(x_{t}^{1}\right.$, is $A^{1} \ldots . . . x_{t}^{k}$ is $\left.A^{k}\right)$ then $y_{t}=h\left(x_{t}^{1}, x^{2}, \ldots x_{t}^{k},\right)$

In this equation, $\mathrm{x}_{\mathrm{t}}{ }^{1}-\mathrm{x}_{\mathrm{t}}^{\mathrm{k}}(\mathrm{x} \in \chi$ : set of all input variables of the fuzzy controller) denotes premise input variables for the fuzzy controller for the time interval $\mathrm{t}\left(\forall t \in T\right.$ ), $\mathrm{y}_{\mathrm{t}}$ denotes output variable of the fuzzy logic controller whose value is inferred. $A^{1}$ denotes the fuzzy sets having a linear membership function representing a fuzzy subspace where rule $\mathrm{R}^{1}$ can be applied. $\mathrm{y}_{\mathrm{t}}^{1}$ is calculated for implication rule $\mathrm{R}^{1}$ using Eq. 14 using the function $\mathrm{h}^{1}$ in the consequence.

$\mathrm{y}_{\mathrm{t}}^{1}=\mathrm{w}_{0}{ }^{1}+\mathrm{w}_{1}{ }^{1} \mathrm{x}_{\mathrm{t}}^{1}+\mathrm{w}_{2}{ }^{1} \mathrm{x}_{\mathrm{t}}^{2} \ldots . .+\mathrm{w}_{\mathrm{k}}{ }^{1} \mathrm{x}_{\mathrm{t}}^{\mathrm{k}}$ 
330 where $\mathrm{w}_{0}{ }^{1}, \mathrm{w}_{1}{ }^{1}((\mathrm{w} \in \mathrm{W}$ : set of decision space variable related to fuzzy controller $(W \subset D))$ denotes coefficient

331 determined by the system designer. $\mathrm{y}_{\mathrm{t}}^{1}$ is further simplified considering the two inputs according to Eq. 15

$332 \mathrm{y}_{\mathrm{t}}{ }^{1}=\left(\mathrm{w}_{1}{ }^{1} \mathrm{x}_{\mathrm{t}}{ }_{\mathrm{t}}+\mathrm{w}_{2}{ }^{1} \mathrm{x}_{\mathrm{t}}{ }_{\mathrm{t}}\right) /\left(\mathrm{w}_{1}{ }^{1}+\mathrm{w}_{2}{ }^{1}\right)$

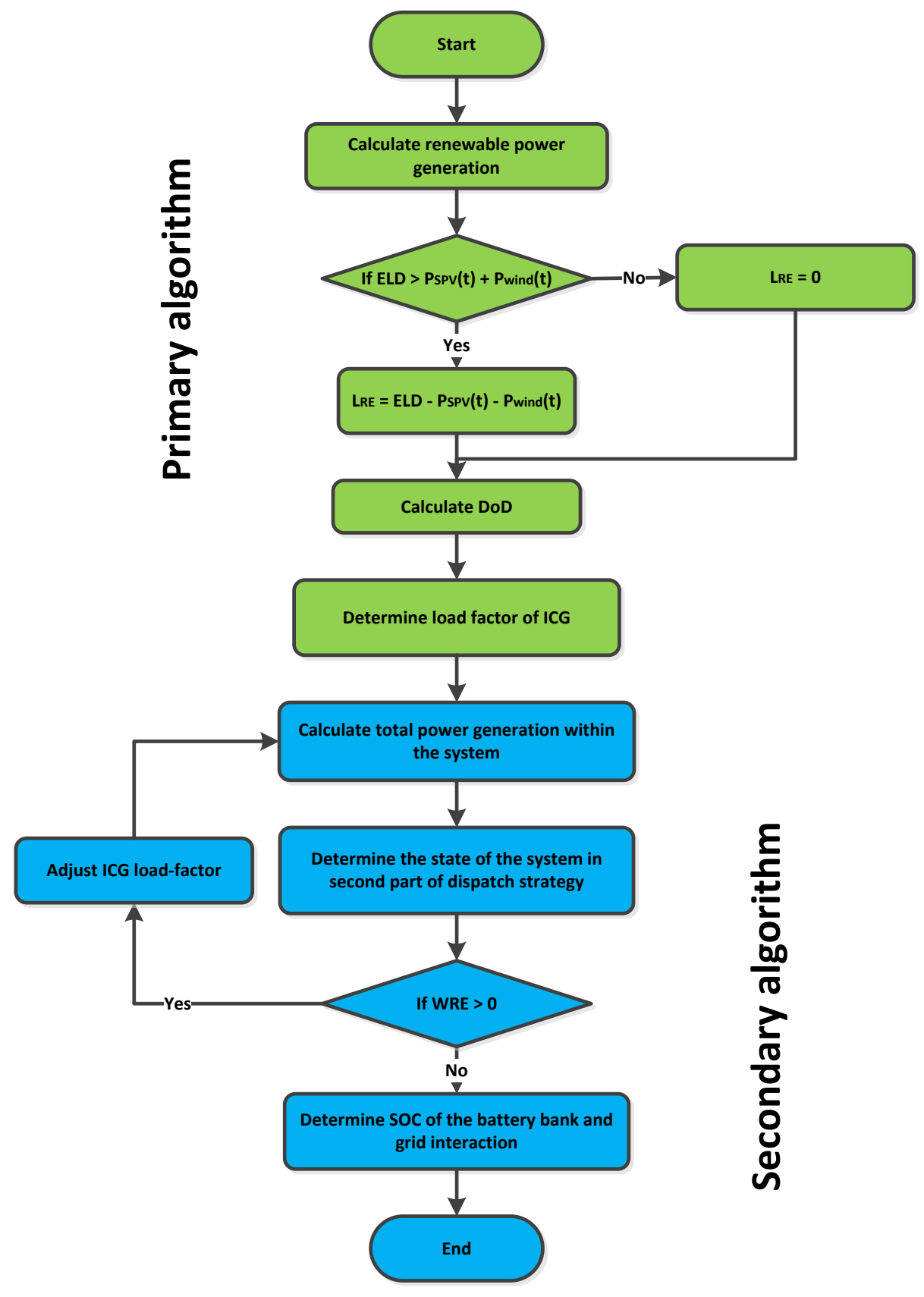

334 Fig. 4: Flow chart of the Dispatch Strategy considering the operation of internal combustion generator, battery bank

and grid interactions 
Finally, $y_{t}$ is calculated using center of gravity method according to Eq. 16 where $\mu_{1}$ denotes the membership function value for the corresponding rule $\mathrm{R}^{1}$.

$338 y_{t}=\frac{\sum \mu_{l} y_{t}^{l}}{\sum \mu_{l}}$

An extended description of this method can be found in Ref. [74]-[77] . The weight coefficients corresponding to all the nine subspaces $(w \in W)$ are optimized using the optimization algorithm considering these as decision space variables. After determining the ICG operating state, the net power generated in the electrical hub is determined by combining both the non-dispatchable and dispatchable energy sources. The mismatch between demand and power generated is calculated afterwards. Load factor of the ICG is adjusted whenever the excess power generation is larger than the available storage capacity of the battery bank and $\mathrm{EG}_{\mathrm{Lim}}$. In the case of demand being larger than the generated power, Load Mismatch (LM) is calculated which is the difference between demand and power generated. The load mismatch is used to determine the operating state of secondary level dispatch strategy.

\subsection{Secondary level dispatch strategy}

Eight main operating system states are identified for the second stage of the dispatch strategy based on the conditions of the input variables for the rule based controller as well as curtailments for grid interactions (Fig. 5). A

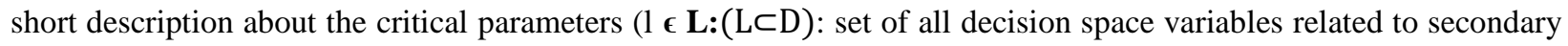
level controller) used to optimize the state transfer is presented in Table 1 followed by a graphical presentation in figure Fig. 6.

The first four operating states corresponds to instances where generation (combining wind, SPV and ICG) is less than the demand of the electrical hub. In State 1, corresponds to the instances where price of electricity in grid is higher $\left(G I_{t}^{I G}\right)>\operatorname{Lim}_{\mathrm{BD}}$ and $\left.G I_{t}^{E G}<\operatorname{Lim}_{\mathrm{BTG}}\right)$ and it is economical to take the mismatch from battery bank. Discharging the battery bank minimizes its life time, especially when reaching lower SOC levels. In order to overcome this problem, a minimal $\mathrm{SOC}$ level, which can be reached during the discharging process $\left(\mathrm{SOC}_{\min }\right)$, is determined using the optimization algorithm. 


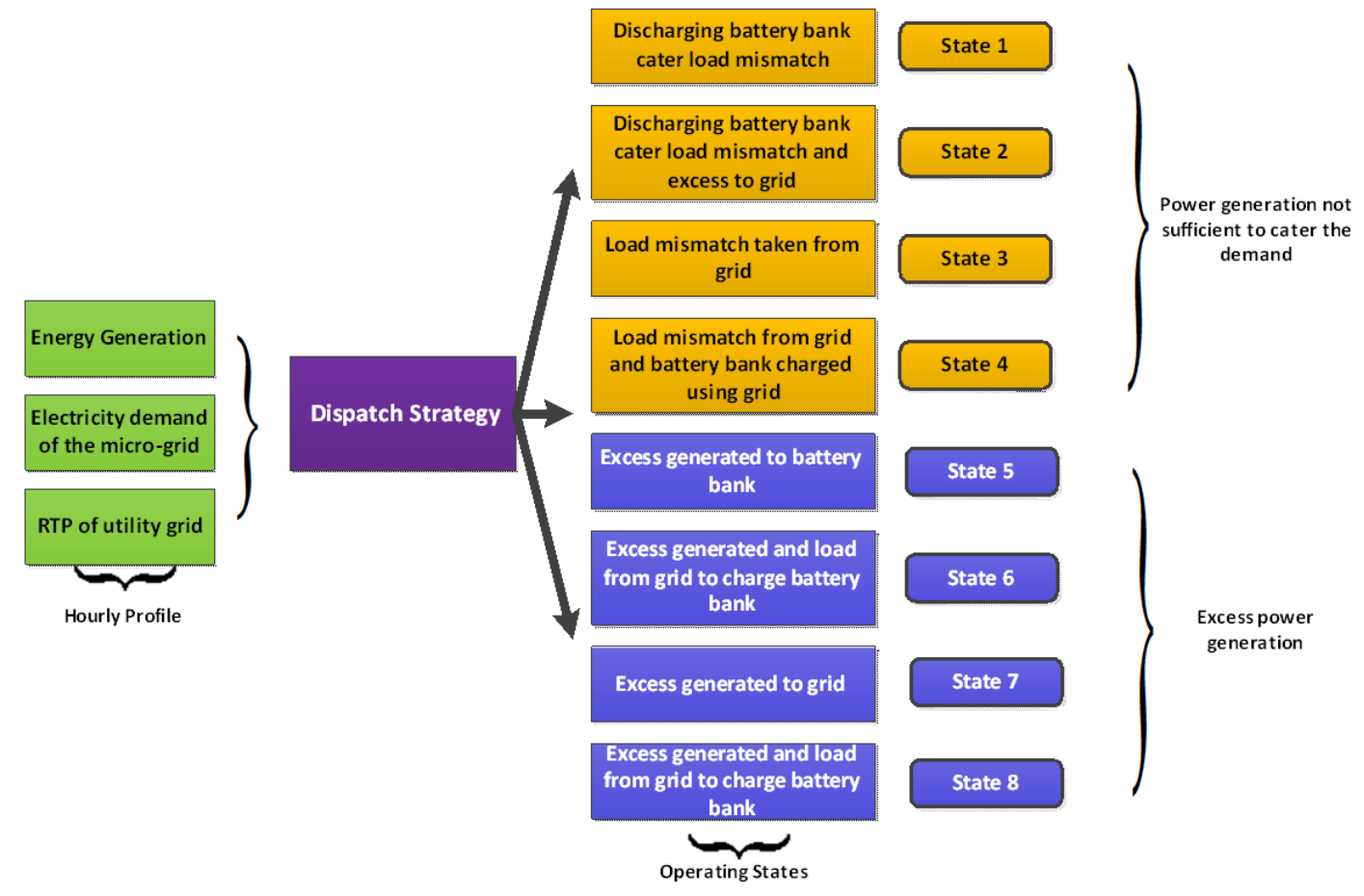

Fig. 5 Operating states of the system

362 When the cost of electricity in the grid increases further, it is economical to discharge the battery bank $\left(G I_{t}^{I G}>\right.$

$363 \operatorname{Lim}_{\mathrm{BD}}$ and $\left.G I_{t}^{E G}>\operatorname{Lim}_{\mathrm{BTG}}\right)$ and sell electricity to the grid while supplying the mismatch between demand and

364 generation. System moves to State 2 in such instances. However, discharging battery bank may lead to instances

365 where electrical hub needs to purchase electricity at a larger price from the grid at a later stage. In addition, depth of

366 discharge of the battery bank needs to be considered since it reduces the lifetime of the battery bank. Hence,

367 minimal SOC for the battery discharging process $\left(\mathrm{SOC}_{\mathrm{Min}, \mathrm{G}}\right)$ needs to be determined through the optimization

368 algorithm.

369 The system operates at State 3, when the price of grid electricity is cheaper $\left(G I_{t}^{I G}<\operatorname{Lim}_{\mathrm{BD}}\right.$ and $\left.\operatorname{Lim}_{\mathrm{GTB}}<G I_{t}^{I G}\right)$.

370 Load mismatch between demand and generation is taken from the grid in State 3. When the price of grid electricity

371 goes down further $\left(G I_{t}^{I G}<\operatorname{Lim}_{\mathrm{BD}}\right.$ and $\left.\operatorname{Lim}_{\mathrm{GTB}}>G I_{t}^{I G}\right)$, it is economical to charge the battery bank using the grid

372 electricity. However, as the charging of the battery bank from the grid reduces their storage capacity for renewable

373 energy, a set point $\left(\mathrm{SOC}_{\mathrm{Set}}\right)$ is introduced as the maximum limit for charging (instead of a full charging the battery

374 bank), similar to the set point in the combined dispatch strategy for hybrid energy systems. SOC Set $_{\text {is optimized }}$ 

algorithm.

Table 1 Brief description about the variables in the dispatch strategy $(1 \in \mathbf{L}(\mathbf{L} \subset \mathrm{D}))$

\begin{tabular}{|c|c|}
\hline $\begin{array}{l}\text { Acronym } \\
\text { used }\end{array}$ & Description \\
\hline $\operatorname{Lim}_{B C}$ & $\begin{array}{l}\text { Critical cost for } \mathrm{GC}_{\mathrm{EG}}(\mathrm{t}) \text { above which selling the excess power generated to the grid } \\
\text { is economical compared to battery charging }\end{array}$ \\
\hline $\operatorname{Lim}_{B D}$ & $\begin{array}{l}\text { Critical cost for } G I_{t}^{I G} \text { below which purchasing power from grid } \\
\text { is economical compared to battery discharging }\end{array}$ \\
\hline $\operatorname{Lim}_{\mathrm{GTB}}$ & $\begin{array}{l}\text { Critical cost for } G I_{t}^{I G} \text { below which purchasing power from grid to charge battery } \\
\text { bank is economical }\end{array}$ \\
\hline $\operatorname{Lim}_{\mathrm{BTG}}$ & Critical cost for $\mathrm{GC}_{\mathrm{EG}}(\mathrm{t})$ above which selling stored energy to grid is economical \\
\hline $\mathrm{SOC}_{\min }$ & $\begin{array}{l}\text { Critical SOC of the battery bank below which discharging is not economical to cater } \\
\text { the load mismatch }\end{array}$ \\
\hline $\mathrm{SOC}_{\mathrm{Min}, \mathrm{G}}$ & $\begin{array}{l}\text { Critical SOC of the battery bank below which it is not economical to discharge and/or } \\
\text { to sell the stored energy to grid }\end{array}$ \\
\hline $\mathrm{SOC}_{\text {Set }}$ & $\begin{array}{l}\text { Maximum state of charged to be reached when charging the battery bank using the } \\
\text { grid }\end{array}$ \\
\hline
\end{tabular}

State 5-8 correspond to instances where generation is in excess compared to the demand. System moves into State 5 when price of grid electricity is low $\left(G I_{t}^{E G}<\operatorname{Lim}_{\mathrm{BC}}\right.$ and $\left.\operatorname{Lim}_{\mathrm{GTB}}<G I_{t}^{I G}\right)$ where excess generation is directed to battery bank. When the price of grid electricity is quite low it is economical to charge the batteries from the grid 382 after charging the battery bank from excess power generated $\left(G I_{t}^{E G}<\operatorname{Lim}_{\mathrm{BC}}\right.$ and $\left.\operatorname{Lim}_{\mathrm{GTB}}>G I_{t}^{I G}\right) . \mathrm{State}_{7}$ corresponds to instances where cost in the grid is competitive compared to charging batteries. In such instances, excess generated will be directed to the grid. When the price of electricity in the grid increases further, it is economical to discharge the battery bank in addition to directing excess electricity generated $\left(G I_{t}^{E G}>\operatorname{Lim}_{\mathrm{BC}}\right.$ and battery bank, $\mathrm{EG}_{\mathrm{Lim}}$ and $\mathrm{IG}_{\mathrm{Lim}}$ which makes the energy interactions more complicated. The logic flow diagram used in the secondary level dispatch strategy consists of 18 states which are based on the main eight states described. 


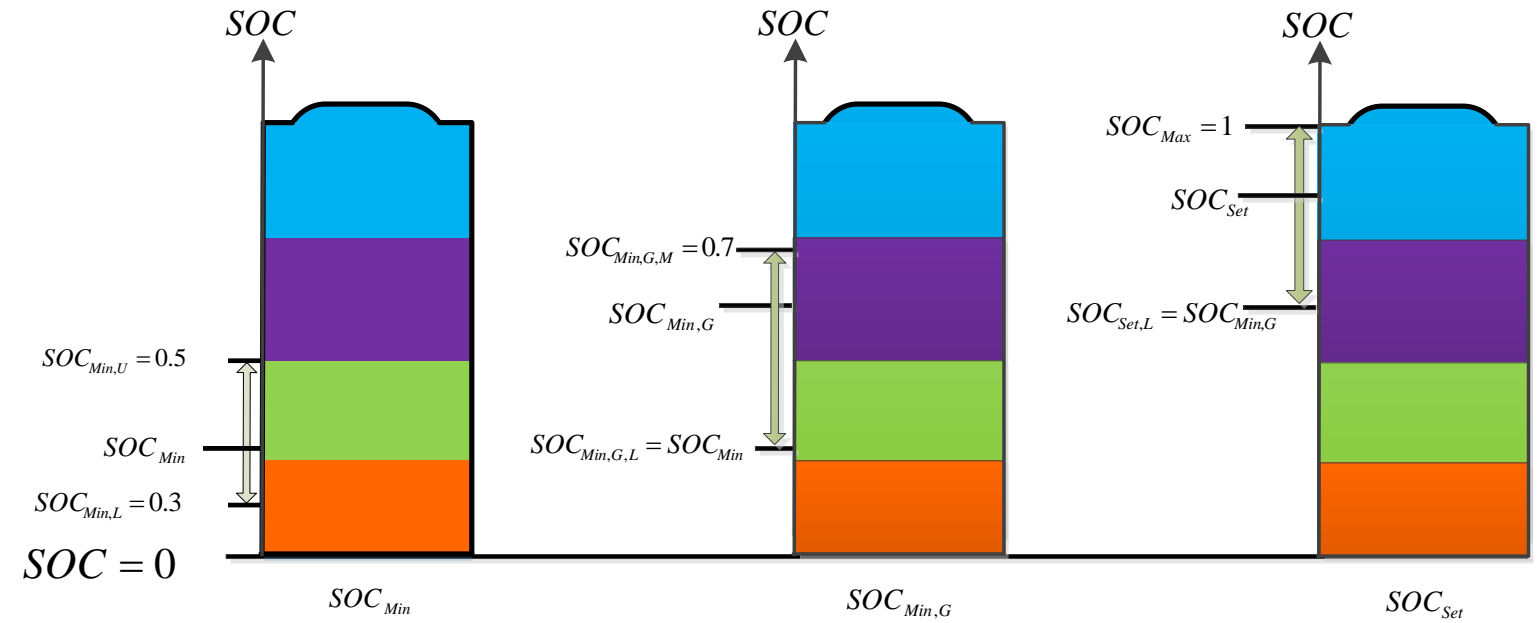

Fig. 6: Selection of the decision space variables for the battery bank

\subsection{Time Series meteorological and demand data for simulation}

392 The hourly average values of wind speed, global horizontal solar irradiation and ambient temperature data are 393 required for the simulation.

\section{$5 \quad$ Optimization of the system design and dispatch strategy}

Designing electric hubs integrated to the grid is challenging due to a number of reasons as discussed before. A heuristic algorithm has been amply used in the literature [19], [32]-[34], [39], [79]-[81] and shown to be much efficient when optimizing these systems when compared to enumerative methods [82] which are used in existing software such as Homer [83]. A detailed comparison of these methods can be found in recent reviews on hybrid energy system designing [80], [84]. This study is using a heuristic algorithm to optimize the system design and dispatch strategy which can handle non-linear objective functions efficiently. This section illustrates optimization algorithm used in this study along with the decision space variables considered for the optimization which are introduced in Section 3 and 4, objective functions considered for the optimization defined in Section 3 and the constraints.

\subsection{Decision space variables}

405 Determining the optimal capacities of the system components as well as the type of components is the main 406 objectives of the optimization algorithm. Basic system components are selected according to Table 2: their 
corresponding type and capacity are also determined using the same optimization algorithm. Six decision space variables are used to represent the whole system configurations.

Optimizing the dispatch strategy is another part of the optimization algorithm. The operation of the ICG and the battery bank need to be optimized together with the grid interaction. Both load mismatch and battery bank SOC are 411 used to determine the state of operation of the ICG. The weight coefficients defined in Section 4.1 are optimized 412 using the same algorithm. Three parameters are used to manage the energy flow to the battery bank according to its 413 State of Charge (SOC) as illustrated in Fig. 6. $\mathrm{SOC}_{\mathrm{Min}}$ is optimized considering a SOC range of [0.3, 0.5]. Critical 414 parameters for battery charging and discharging are optimized considering upper and lower bounds as shown in Fig.

415 6. Similarly four variables are used to control the grid interaction as explained in Section 3.3. A total number of 19 416 decision space variables are selected to represent the state transfer function, with their span is defined according to 417 Table 2.

\begin{tabular}{|c|c|c|c|c|}
\hline Variable & Lower bound & Upper bound & Interval & Description \\
\hline SPV Type $\left({ }^{\text {NTY-SPV }}\right)$ & 0 & 3 & 1 & $\begin{array}{l}\text { Mono-crystaline, } \\
\text { Polycrystaline and } \\
\text { Amorphous }{ }^{1}\end{array}$ \\
\hline \# SPV Panels $\mathrm{N}_{\mathrm{SPV}}$ & 0 & 120 & 1 & $0-30^{1} \mathrm{~kW}$ \\
\hline Type of Turbines $\left(\mathrm{N}^{\mathrm{TY}-\mathrm{W}}\right)$ & 0 & 2 & 1 & $1,5 \mathrm{~kW}$ \\
\hline \# Wind Turbines & 0 & 15 & 1 & $1-75^{2} \mathrm{~kW}$ \\
\hline \# Battery banks & 0 & 20 & 1 & $0-240^{3} \mathrm{kWh}$ \\
\hline ICG Capacity (kVA) & 0 & 15 & 0.5 & $0-7.5 \mathrm{kVA}$ \\
\hline $\mathrm{W}_{\mathrm{i}, \mathrm{j}}$ (weight matrix) & $0 \%$ & $100 \%$ & Continuous & \\
\hline $\mathrm{SOC}_{\mathrm{Min}}$ & $30 \%$ & $50 \%$ & Continuous & \\
\hline $\mathrm{SOC}_{\mathrm{Min}, \mathrm{G}}$ & $\mathrm{SOC}_{\mathrm{Min}}$ & $70 \%$ & Continuous & \\
\hline $\mathrm{SOC}_{\text {set }}$ & $\mathrm{SOC}_{\mathrm{Min}, \mathrm{G}}$ & $100 \%$ & Continuous & \\
\hline $\operatorname{Lim}_{B C}$ & $0 \%$ & $100 \%$ & Continuous & \\
\hline $\operatorname{Lim}_{\mathrm{GTB}}$ & $0 \%$ & $\operatorname{Lim}_{B C}$ & Continuous & \\
\hline $\operatorname{Lim}_{B D}$ & $0 \%$ & $100 \%$ & Continuous & \\
\hline $\operatorname{Lim}_{\text {BTG }}$ & $\operatorname{Lim}_{B D}$ & $100 \%$ & Continuous & \\
\hline
\end{tabular}




\subsection{Objective functions and constraints considered}

423 The goal of this study is to maximize the autonomy of the system in renewable energy integration process while 424 minimizing its cost. It is a multi-objective optimization task where two objective functions need to be minimized 425 simultaneously. All three indicators introduced in Section 3.2 are used as the objective functions along with LEC 426 introduced in Section 3.4. LOLP is considered as a constraint (defined in Section 3.3) in the optimization algorithm. 427 List of objective functions considered considering different scenarios are presented in Table 3.

\begin{tabular}{|c|c|c|c|}
\hline Scenario $^{*}$ & $\begin{array}{l}\text { Objective Function } 1 \text { - } \\
\text { Objective Function } 2 \\
\left(\mathrm{~F}_{1}-\mathrm{F}_{2}\right)\end{array}$ & Sensitivity & Constraints \\
\hline A & $\begin{array}{c}\text { LEC-Grid Interactions } \\
\text { considering imports }\left(\mathrm{GI}_{\mathrm{IG}}\right)\end{array}$ & Not considered & \\
\hline A & $\begin{array}{c}\text { LEC-Grid Interactions } \\
\text { considering Exports }\left(\mathrm{GI}_{\mathrm{EG}}\right)\end{array}$ & Not considered & $\begin{array}{l}\text { Loss of load } \\
\text { probability }\end{array}$ \\
\hline A & $\begin{array}{c}\text { LEC-Grid Interactions } \\
\text { considering imports }\left(\mathrm{GI}_{\mathrm{IEG}}\right)\end{array}$ & Not considered & (LOLP) \\
\hline B & $\begin{array}{c}\text { LEC-Grid Interactions } \\
\text { considering imports }\left(\mathrm{GI}_{\mathrm{IG}}\right)\end{array}$ & $\begin{array}{l}\text { Grid curtailments considering } 30 \%, 60 \% \text { and } 90 \% \\
\text { of the peak demand }\end{array}$ & \\
\hline B & $\begin{array}{c}\text { LEC-Grid Interactions } \\
\text { considering imports }\left(\mathrm{GI}_{\mathrm{IG}}\right)\end{array}$ & $\begin{array}{l}\text { Market price of SPV panels and wind turbines } \\
\text { considering } 10 \%, 20 \% \text { and } 30 \% \text { reduction }\end{array}$ & \\
\hline B & $\begin{array}{c}\text { LEC-Grid Interactions } \\
\text { considering imports }\left(\mathrm{GI}_{\mathrm{IG}}\right)\end{array}$ & $\begin{array}{l}\text { Market price of grid electricity considering } 10 \% \text {, } \\
20 \% \text { and } 30 \% \text { reduction }\end{array}$ & \\
\hline
\end{tabular}

\subsection{Optimization algorithm}

As discussed in Section 2.3, optimization algorithm is closely connected with the mathematical model and simulation of the system. The computational model and lifecycle simulation which map decision space variables into the objective space are described in detail in Sections 2, 3 and 4. Fig. 7 presents the simplified flow diagram of the optimization algorithm used in this study. The optimization algorithm starts with the random creation of decision vectors including variables related to system design and operation strategy which will create the initial population.

437 Subsequently, set of vectors selected as the initial population is mapped to the objective space through the computational model and the life cycle simulation presented in Section 3 and Section 4 which will provide the 
values for the objective functions $(\mathrm{F} \epsilon \mathrm{F})$ and constraints. Initial archive is created from the non-dominant set of solutions in the population according to the criterion defined by Deb et-at [85]. A Steady $\varepsilon$-State Evolutionary

441 Algorithm [86] is used in this study for updating of archive and reproduction of the population which is proven as a 442 method to maintain the diversity while reaching the final set of Pareto solutions within short period of time. 443 Polynomial mutation operator [87] and simulated binary crossover operator [88] are used along with differential 444 evolutionary operators [77]-[79]in the reproduction of the population. Constraints for the optimization algorithm are 445 handled at two different levels: constraint tournament method [87] is used to handle the constraints in the 446 optimization algorithm and loss of load probability is considered as a constraint while states of the control system 447 were defined to handle the constraints due to grid curtailments. A computer program is written in C++ using Visual 448 studio plat form. Computational time for the Pareto front depends on the objective functions selected and the 449 number of generations considered; on average computational time was two hours for both Scenario A and B in this study.

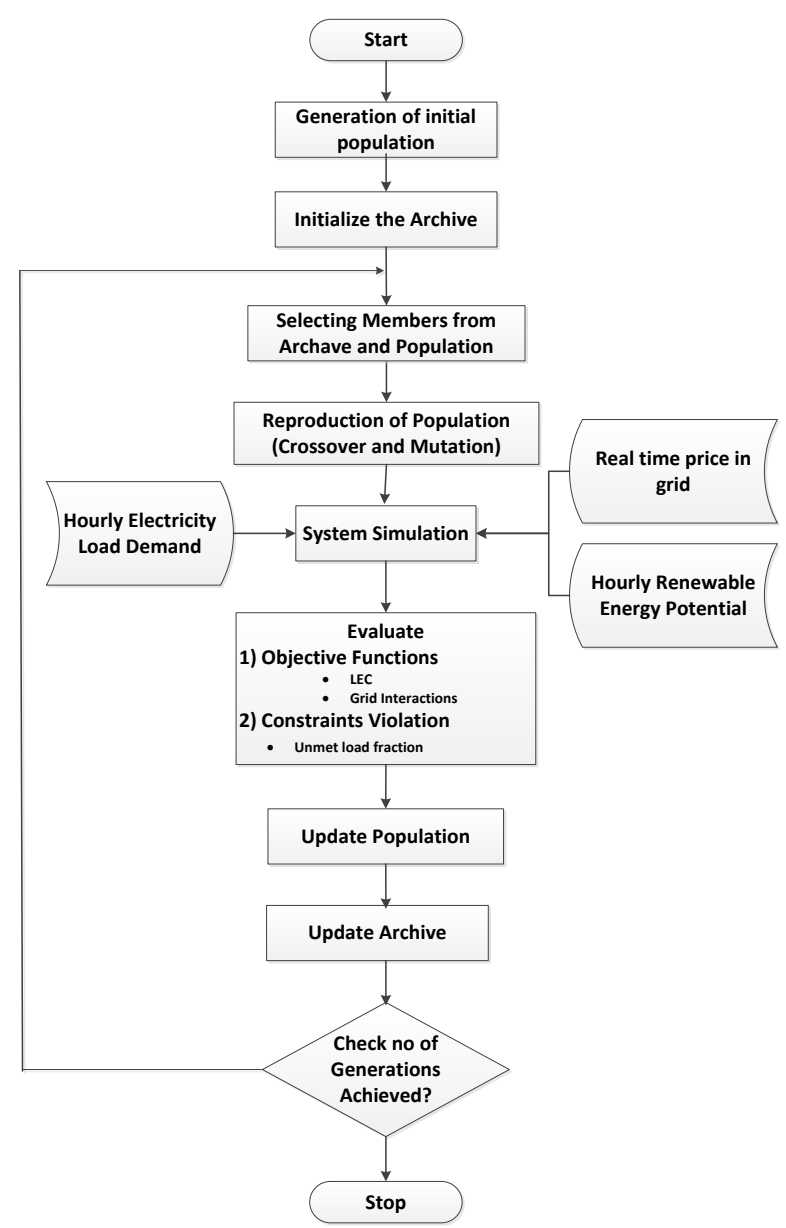




\section{4) Convergence patterns for the optimization Process}

454 Evolutionary algorithm has been amply used in recent past when optimizing energy systems. When it comes to multi 455 objective optimization you need to guarantee the diversity of the Pareto front while guaranteeing that you reach the 456 optimum [92]. Hence, convergence pattern of the Pareto front is usually presented to get an understanding of the 457 progress of the optimization with number of generations in the optimization algorithm. Fig. 8 presents the 458 convergence pattern for LEC-GI IG Pareto front. It is clear that Pareto front is well settled when reaching 200000 459 generations (which is used for all the other optimization problems).

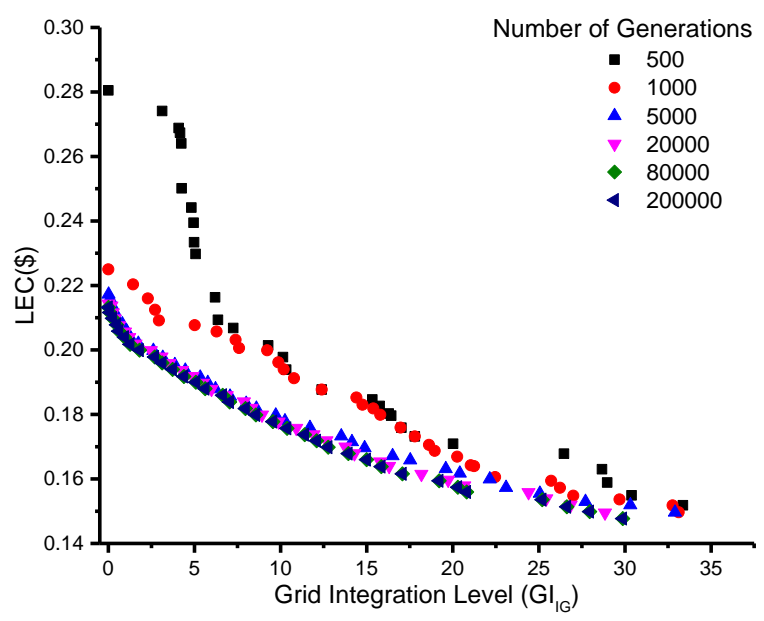

Fig. 8 Convergence pattern of the Pareto front

\section{Results and discussion}

464 Selecting optimum combination of energy technologies, storage becomes vital in integrating SPV and wind energy 465 into electrical hubs. Autonomy of the system needs to be maximized in integrating renewable energy technologies 466 while minimizing the lifecycle cost of the system. Pareto fronts obtained in Section 5 considering LEC and grid 467 integration level is useful in this regard. These Pareto fronts are used in this section to analyze

1) sensitivity of imports, exports and both to lifecycle cost, energy mix and renewable energy utilization of the system 
Accordingly, this section is divided into three parts. A brief overview about the case study is presented in Section 6.1. The impact of grid interactions on electrical hub and energy flow is discussed in Section 6.2. Section 6.3 is devoted to a sensitivity analysis of other techno-economical parameters impacting the results.

\subsection{Overview about the case study}

The site of Hambantota, a south coastal city of Sri Lanka, was considered for this study due to its strong wind and solar energy potential. All the aforementioned meteorological data are issued from the corresponding local meteorological station. The demand of a particular application is highly specific to the latter. In this study, demand is considered to vary according to the load variation suggested by the IEEE system reliability committee [78]. Load profiles are generated following a summer-weekly demand since seasonal demand variations are trivial in Sri Lanka being located near to the equator.

The cost of electricity is a function of time in a smart grid, depending from several factors. A hypothetical cost function is considered for the hourly electricity prices based on the demand in the region. Hourly electricity price is assumed to be proportional to the electricity consumption in the region, a maximal cost of electricity being reached at the peak hours of the demand. The price for selling electricity to the grid is considered to be proportional to the purchasing price of electricity from the grid. A sensitivity analysis of the impact of the cost of electricity function on the optimal solution was subsequently carried out. The effect of demand curve and the profile of grid cost on optimum system design are to be presented in future publications.

\subsection{Sensitivity of grid interactions and energy mix}

The support of the grid is essential to maintain the power supply reliability of the electrical hub with the integration of renewable energy sources, while minimizing the lifecycle costs. Maximizing the autonomy of the electrical hub is important when considering the grid. Therefore, the lifecycle cost and the autonomy of electrical hub may become conflicting, meaning that it can be difficult to optimize both of them simultaneously. A Pareto front presents all the possible combination of solutions, which are optimal and non-dominant between each other. It helps the system designers to better understand the characteristics of the system accounting for the changes at the grid integration level. 
Three different performance indicators were introduced in this study to assess the grid integration level, as defined in Section 3.3. Three Pareto fronts are computed taking levelized energy cost (LEC) and grid integration (LEC-GI) as objective functions, considering the import and export limits for the grid interactions as $50 \%$ of the peak demand of the hub. The Pareto fronts which are calculated and plotted in Fig. 9 correspond to the three different methods for grid interactions with LEC. LEC-GI $\mathrm{IG}_{\mathrm{G}}$ denotes Pareto front obtained considering LEC and electricity imports from

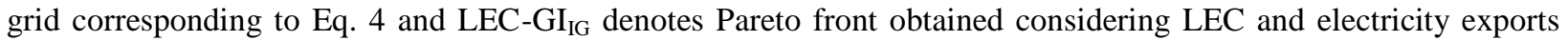
(Eq. 5). Finally, LEC-GI IEG Pareto front considers interactions in both modes along with LEC as objective functions. low throughout LEC-GI $\mathrm{EG}_{\mathrm{EG}}$ (exporting) Pareto front compared to the other two. LEC notably increases in LEC-GI $\mathrm{IEG}_{\mathrm{I}}$ Pareto front when grid interactions are less than $5 \%$ which is the same for LEC-GI $I_{\mathrm{EG}}$. Set of solutions in LEC-GI $\mathrm{IEG}_{\mathrm{I}}$ Pareto front follows the trend of $\mathrm{LEC}-\mathrm{GI}_{\mathrm{IG}}$ when grid interactions are greater than $5 \%$. These variations are mainly due to the differences of power generation mix and modes of grid interactions which are taken into discussion in

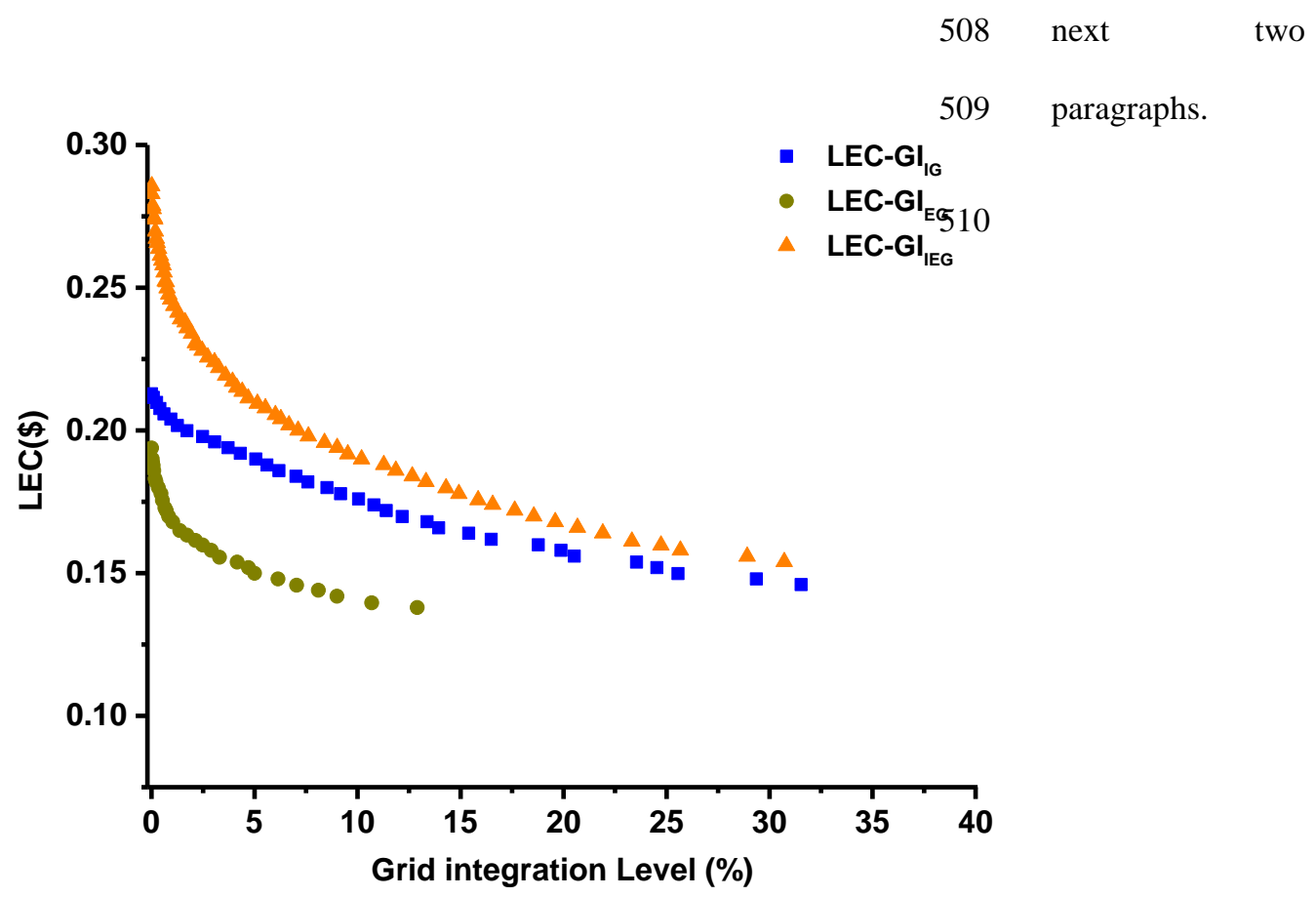


In order to analyze the import, export and both interactions with the grid simultaneously, $\mathrm{GI}_{\mathrm{IG}}, \mathrm{GI}_{\mathrm{EG}}$ and $\mathrm{GI}_{\mathrm{IEG}}$ are plotted for three Pareto fronts considering all the modes of interactions with grid as a percentage of annual demand ( Fig. 10). Among the three Pareto fronts, percentage exports to the grid $\left(\mathrm{GI}_{\mathrm{EG}}\right)$ remains almost constant in $\mathrm{LEC}-\mathrm{GI}_{\mathrm{IG}}$ Pareto front. Meanwhile, $\mathrm{GI}_{\mathrm{IG}}$ gradually reduces in with the increase of grid interactions in LEC-GI $\mathrm{EG}_{\text {Pareto front. }}$ However, GI $\mathrm{I}_{\mathrm{IEG}}$ is notably high (above 45\%) in LEC-GI $\mathrm{EG}_{\mathrm{E}}$ Pareto front when compared to LEC-GI $\mathrm{I}_{\mathrm{IG}}$ Pareto front. This result in higher LEC in LEC-GI $\mathrm{IG}_{\text {Pareto front compared to LEC-GI }}$ EG which is observed in Fig. 9. Energy

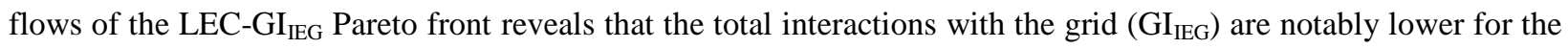

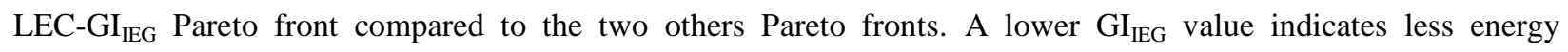
interactions with the grid. This implies that the electrical hub tends accordingly to operate as a standalone system in this case where variations of the renewable energy supply and the demand are absorbed by the system itself resulting higher LEC due to the less interactions with the energy market through the grid.

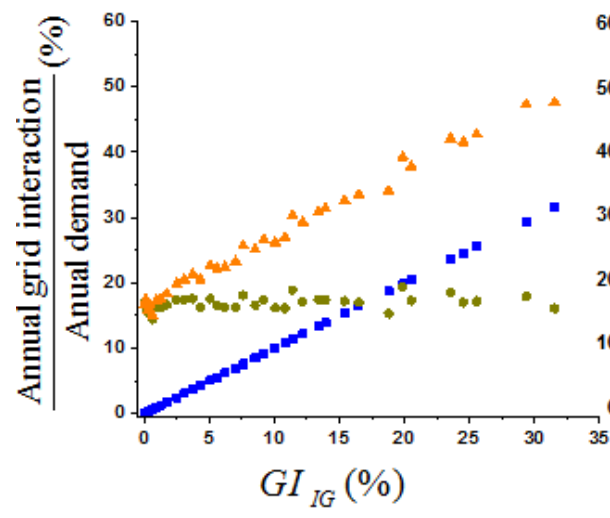

LEC-Glıg (Import from the grid)

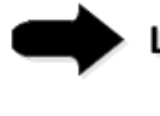

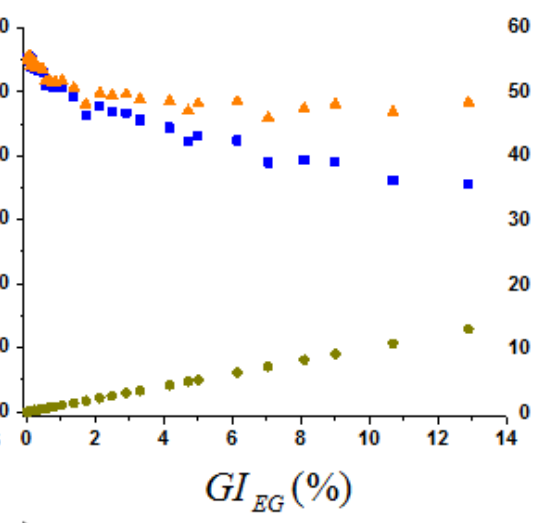

LEC-Gleg (Export to the grid)
- FG

- TG

TFG

Fig. 10: Comparison of the energy interactions with the grid (import, export and both) for three Pareto fronts (LEC$\mathrm{GI}_{\mathrm{IG}}, \mathrm{LEC}-\mathrm{GI}_{\mathrm{EG}}, \mathrm{LEC}-\mathrm{GI}_{\mathrm{IEG}}$ from left to right) obtained considering LEC and grid interactions

Analyzing the power generation within the electrical hub from SPV panels and the wind turbines is one of the main

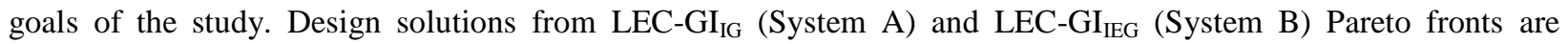
selected in order to achieve this objective. The power generation from the non-dispatchable energy sources (SPV panels and wind turbines), the dispatchable energy source (ICG) as well as the total electrical power generated are plotted for both systems in Fig. 11 as a fraction of total annual demand of the electrical hub. From the two Pareto 
fronts, it can be argued that the grid integration of wind and solar energy technologies through the electrical hubs is achieved in a satisfactory way being more than $60 \%$ of the annual demand of the hub. System B shows annual wind and solar energy contributions larger than $100 \%$ (as a percentage of total annual demand). Minimal contributions from SPV and wind turbines reach $80 \%$ for System A in the corresponding Pareto front. More importantly, there are instances in which SPV and wind contributions are larger than the annual electricity demand, the electrical hub operating as an "Energy plus" (generating more than the annual demand) system in both cases. However, it is important to analyze the Wasted Renewable Energy (WRE) due to limitations in energy storage and grid curtailments along with the generation to get a proper overview of the system.

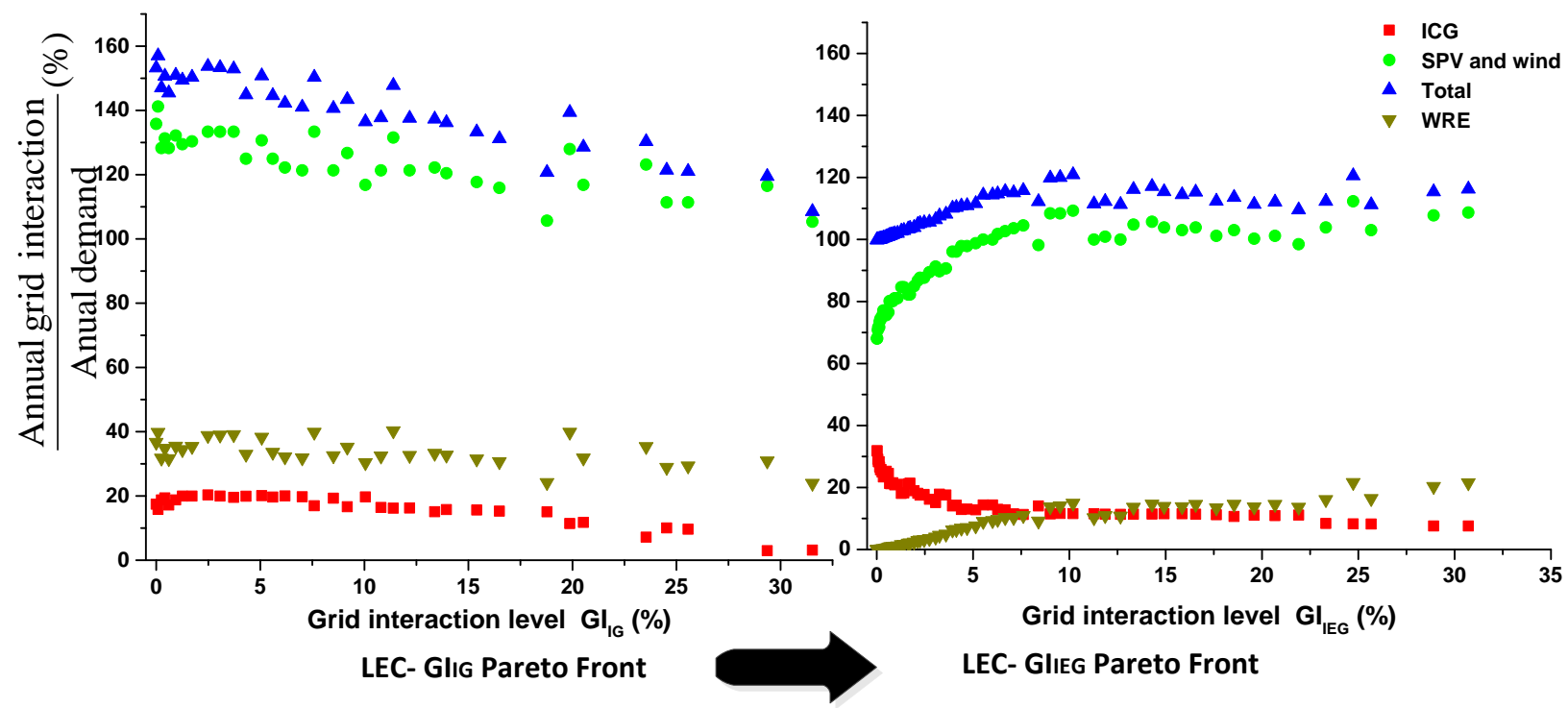

Fig. 11: Power generation using ICG, SPV panels and wind turbines for optimal systems in the LEC-GI $I_{\mathrm{IG}}$ and LEC$\mathrm{GI}_{\mathrm{IEG}}$ Pareto fronts (left System A and right System B)

When considering the WRE of System A, it is clear that around 30-40\% renewable energy generated will be lost due to limitations in storage and grid interactions which reach up to $20 \%$ in System B. In addition, around $15 \%$ of the generation within the system is exported in System A. Considering the generation, WRE and fraction exported to the grid; around $60-85 \%$ of the demand of the electrical hub is catered using non-dispatchable energy sources. Considering the economic scenario (lowest LEC) it reaches around 60\%. This is a major achievement when compared to the level of non-dispatchable renewable energy contribution in present cases which will be around 20- 
$30 \%$ [49] in direct integration to grid. This clearly demonstrates the potential of electrical hub to integrate nondispatchable renewable energy sources. Nonetheless, it is important to highlight that utilizing renewable energy is a major challenge in electrical Hubs although higher integration levels can be achieved.

Both plots show that the ICG plays a major role whenever grid interaction is weak. For System B, a dispatchable energy source is essential in order to minimize the grid interactions further and to operate in an autonomous way. An electrical hub based only on non-dispatchable energy sources and energy storage is not economically sound when a perfect autonomy is targeted. Contributions from the ICG are gradually mitigated with the increase of grid interaction, reaching a condition where it is economically justified to operate the system without it.

\subsection{Role of dispatchable source and storage}

Eight systems were picked-up at different locations of the two Pareto fronts showing $\mathrm{GI}_{\mathrm{IG}}$ close to each other and tabulated in Table 4. Power generation mix of the electrical hub and interactions with the grid are tabulated as the percentage of the annual demand from the electrical hub. All the design solutions show SPV and wind energy generation larger than $67 \%$ of the annual demand of the electrical hub, which is a significant figure compared to the current low penetration of renewable energy sources. Contribution from the ICG does not show a major change in the set of solutions from LEC-GI ${ }_{I G}$ Pareto front. Nonetheless, power generation from ICG increases from $11 \%$ up to $32 \%$ in the case of minimizing the grid interactions in LEC-GI $\mathrm{IEG}_{\mathrm{IE}}$ Pareto front.

The two Pareto fronts show a notable difference in the battery bank size: in LEC-GI IG Pareto front the capacity of battery bank has increased from 84 to $156 \mathrm{kWh}$ when moving from A-IG to D-IG while it has increased from 156 to $228 \mathrm{kWh}$ when moving from A-IEG to D-IEG. In contrast, Renewable Energy Capacity (REC) varies from 52.75 $\mathrm{kW}$ to $56.75 \mathrm{KW}$ in the design solutions of $\mathrm{LEC}_{-\mathrm{GI}_{\mathrm{IG}}}$ Pareto front while it varies from $20.75 \mathrm{~kW}$ to $41.5 \mathrm{~kW}$ in the

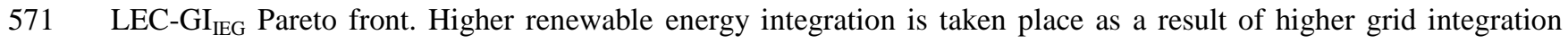
572 level which is notably high in LEC-GI $I_{\mathrm{IG}}$ Pareto front compared to the other. However, wasted renewable energy is 573 quite high in solutions of LEC-GI $I_{I G}$ Pareto front when compared to solutions of LEC-GI $I_{I G}$ Pareto front. This 574 indicates that although grid assists the renewable energy integration, battery bank play a major role in maximizing utilization of renewable energy. 
Table 4: Configuration and energy flow analysis for different electrical hub systems from LEC-GI ${ }_{I G}$ LEC-GI $_{\text {IEG }}$

\begin{tabular}{|c|c|c|c|c|c|c|c|c|c|c|c|}
\hline & & $\begin{array}{c}\text { LEC } \\
(\$)\end{array}$ & $\begin{array}{c}\mathrm{GI}_{\mathrm{IG}} \\
(\%)\end{array}$ & $\begin{array}{c}\mathrm{GI}_{\mathrm{EG}} \\
(\%)\end{array}$ & $\begin{array}{l}\text { SPV } \\
(\%)\end{array}$ & $\begin{array}{c}\text { Wind } \\
(\%)\end{array}$ & $\begin{array}{c}\text { ICG } \\
(\%)\end{array}$ & $\begin{array}{c}\text { WRE } \\
(\%)\end{array}$ & $\begin{array}{l}\text { REC } \\
(\mathrm{kW})\end{array}$ & $\begin{array}{l}\text { Battery } \\
(\mathrm{kWh})\end{array}$ & $\begin{array}{c}\text { ICG } \\
\text { Capacity } \\
\text { (kVA) }\end{array}$ \\
\hline \multirow{4}{*}{ 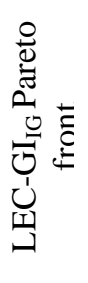 } & A-IG & 0.188 & 5.60 & 16.61 & 13.56 & 111.38 & 19.65 & 33.60 & 53.75 & 84 & 3.5 \\
\hline & B-IG & 0.200 & 1.72 & 16.65 & 18.98 & 111.38 & 19.93 & 35.40 & 55.25 & 96 & 3.5 \\
\hline & C-IG & 0.206 & 0.61 & 14.47 & 28.01 & 100.25 & 17.17 & 31.60 & 52.75 & 132 & 3.5 \\
\hline & D-IG & 0.213 & 0.00 & 16.58 & 24.40 & 111.38 & 17.44 & 36.68 & 56.75 & 156 & 4.5 \\
\hline \multirow{4}{*}{ 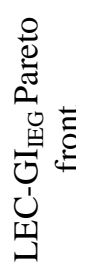 } & A-IEG & 0.188 & 5.01 & 6.26 & 44.28 & 55.69 & 11.49 & 10.24 & 37.25 & 156 & 3.5 \\
\hline & B-IEG & 0.192 & 1.77 & 7.75 & 41.57 & 66.83 & 11.61 & 14.07 & 41.5 & 156 & 3.5 \\
\hline & C-IEG & 0.204 & 0.62 & 5.67 & 46.09 & 55.69 & 12.93 & 9.69 & 37.75 & 180 & 4 \\
\hline & D-IEG & 0.286 & 0.00 & 0.01 & 56.93 & 11.14 & 31.79 & 0.00 & 20.75 & 228 & 5 \\
\hline
\end{tabular}

578

A notable increase in energy storage and contribution from ICG results sudden price increase in LEC when moving from LEC-GI IG Pareto front to $\mathrm{LEC}-\mathrm{GI}_{\mathrm{IEG}}$ Pareto front. On the other hand, the battery bank capacity remains comparable for the design solutions of the LEC-GI IEG Pareto front although a $20 \%$ reduction in ICG power generation is observed with an increase of grid interactions. To conclude, the battery bank can be economically justified if it absorbs the fluctuations of renewable energy sources and the demand providing higher grid interactions occurs, leading to a different role for an ICG integrated in an electrical hub.

\subsection{Sensitivity of grid curtailments, energy market and market price of RE technologies}

A Pareto multi-objective optimization is conducted in this section, considering $\mathrm{LEC}$ and $\mathrm{GI}_{\mathrm{IG}}$ as objective functions, to evaluate the sensitivity of grid curtailments of $30 \%, 60 \%$ and $90 \%$ of the maximal demand for the electrical hub. The optimization is conducted for both importing and exporting electricity to and from the electrical hub. The Pareto fronts for these grid curtailments are presented in Fig. 12 (three Pareto fronts corresponding to three cases are plotted in the same diagram). Generation mix and the grid interactions of each Pareto front are plotted separately.

The results show that increasing the upper limit for grid curtailments allow tight energy interactions with the energy market which result in a notable reduction in $\mathrm{LEC}$. $\mathrm{GI}_{\mathrm{IG}}$ varies from $10-20 \%$ to $60-70 \%$ with the increase of upper 
curtailments for grid interactions. More importantly, power generation in the electrical hub, through wind turbines and SPV panels, is notably increased when considering as a percentage of annual demand. This clearly demonstrates that the electrical hubs actively participate to the energy market while playing a role in generating the supply of the micro-grid with an increase of the grid interaction limits. Widening the grid curtailments minimizes the role of the the electrical hub.

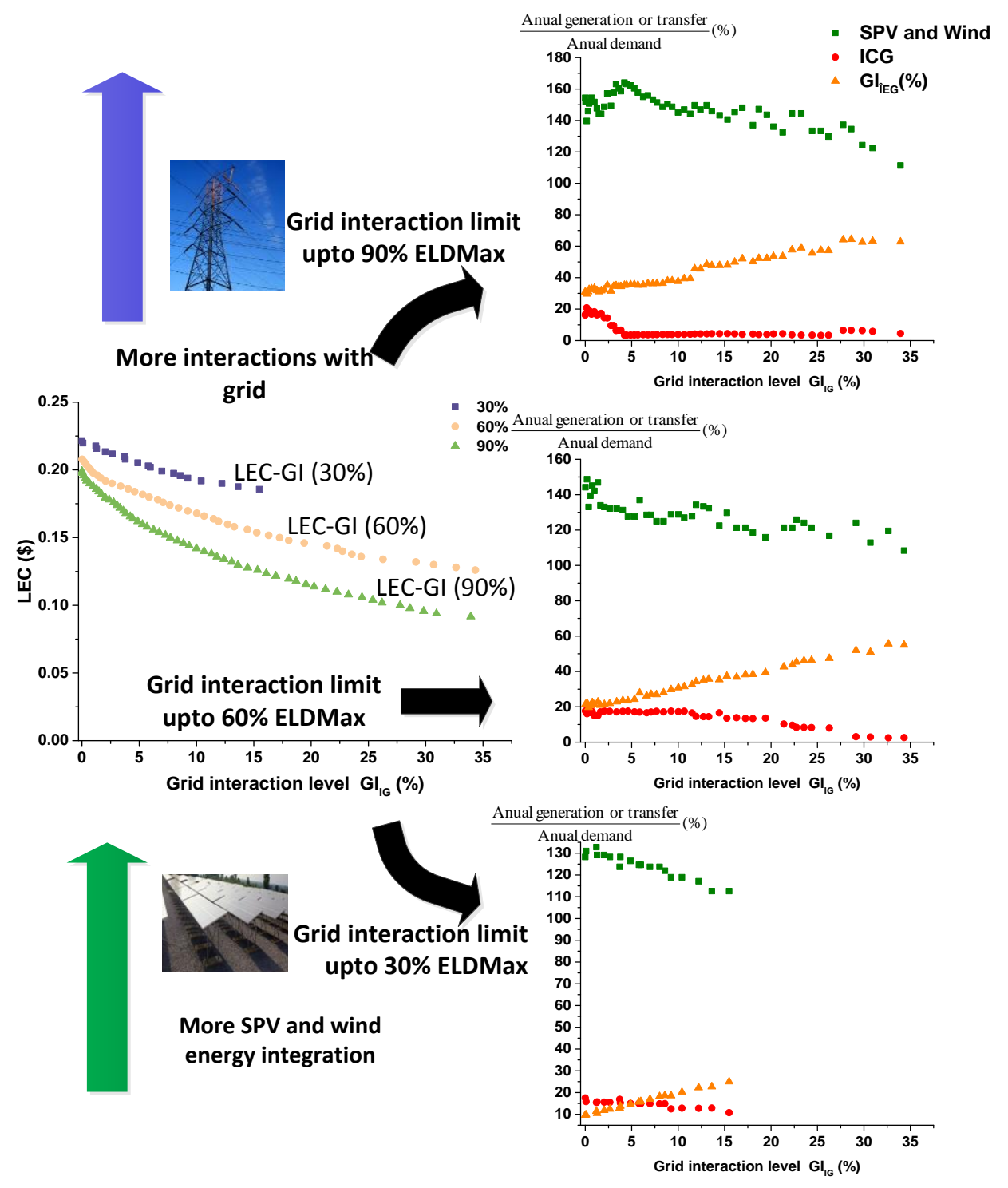

600 Fig. 12: LEC-grid integration Pareto front with 30\%, 60\% and 90\% upper bounds for grid interactions (Left had side 601 Pareto fronts) and corresponding generation mix (Right hand side top to bottom $90 \%$ to $30 \%$ grid curtailments) and 
The influence of a reduction in market price for both wind turbines and SPV panels was assessed in this study simultaneously, instead of conducting a detailed study and considering each component separately (Fig. 13). LEC$\mathrm{GI}_{\mathrm{IG}}$ Pareto fronts are obtained considering a 10\%, 20\% and 30\% (taken as $\mathrm{P}, \mathrm{Q}$, R respectively) price reduction in SPV panels and wind turbines. A notable reduction in LEC is observed with a drop of market prices for both renewable energy technologies, as shown in Fig. 13. Sensitivity bars are introduced assuming a $10 \%$ relative increase or reduction in the analysis of the Pareto front. Sensitivity bars indicate that uniform reduction in LEC is observed with $10 \%(\mathrm{P})$ price reduction in renewable energy components. A notable reduction in LEC is observed when moving from $\mathrm{P}$ to $\mathrm{Q}$ and subsequently to $\mathrm{R}$ which is uniform throughout the Pareto front.

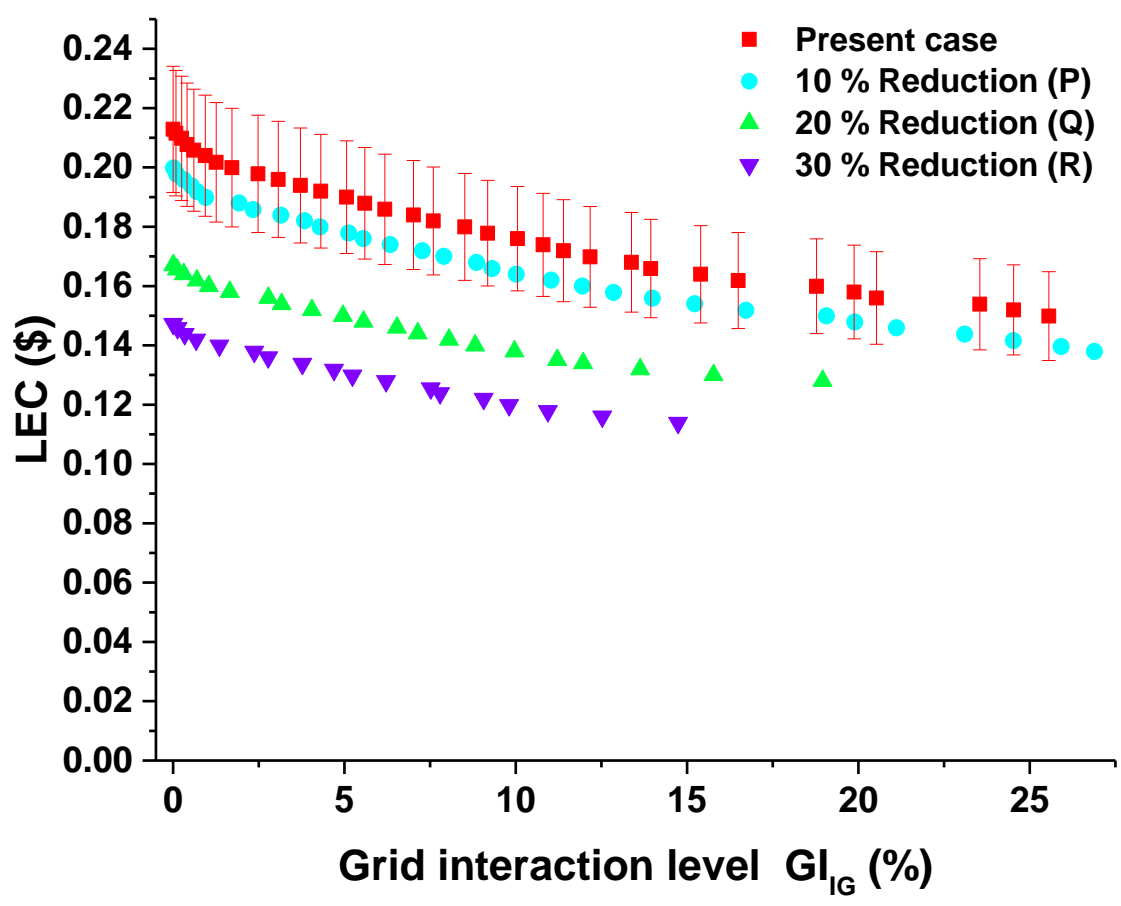

Fig. 13: Sensitivity analysis of market prices of wind turbines and SPV panels on the LEC-GI $\mathrm{I}_{\mathrm{IG}}$ Pareto front

Finally, Pareto multi objective optimization is conducted considering LEC-GI $I_{\mathrm{IG}}$ assuming a $10 \%, 20 \%$ and $30 \%$ reduction in the hourly cost of energy profile. Pareto fronts obtained from the optimization are presented in Fig. 14. It can be observed that the LEC rises with a reduction of the COE. This looks particularly the case for a $30 \%$ and $20 \%$ cost of energy reduction for instances grid interaction is lower than $25 \%$. This can be explained by using the energy interactions with the grid (Fig. 10). The set of optimal systems located in the LEC-GI $\mathrm{IG}_{\text {Pareto front }}$ maintains strong interactions with the grid by selling to the main grid the excessive amount of renewable energy produced by the electrical hub (refer Fig. 10). In most of the instances, the power generation within the system is 

competitive.

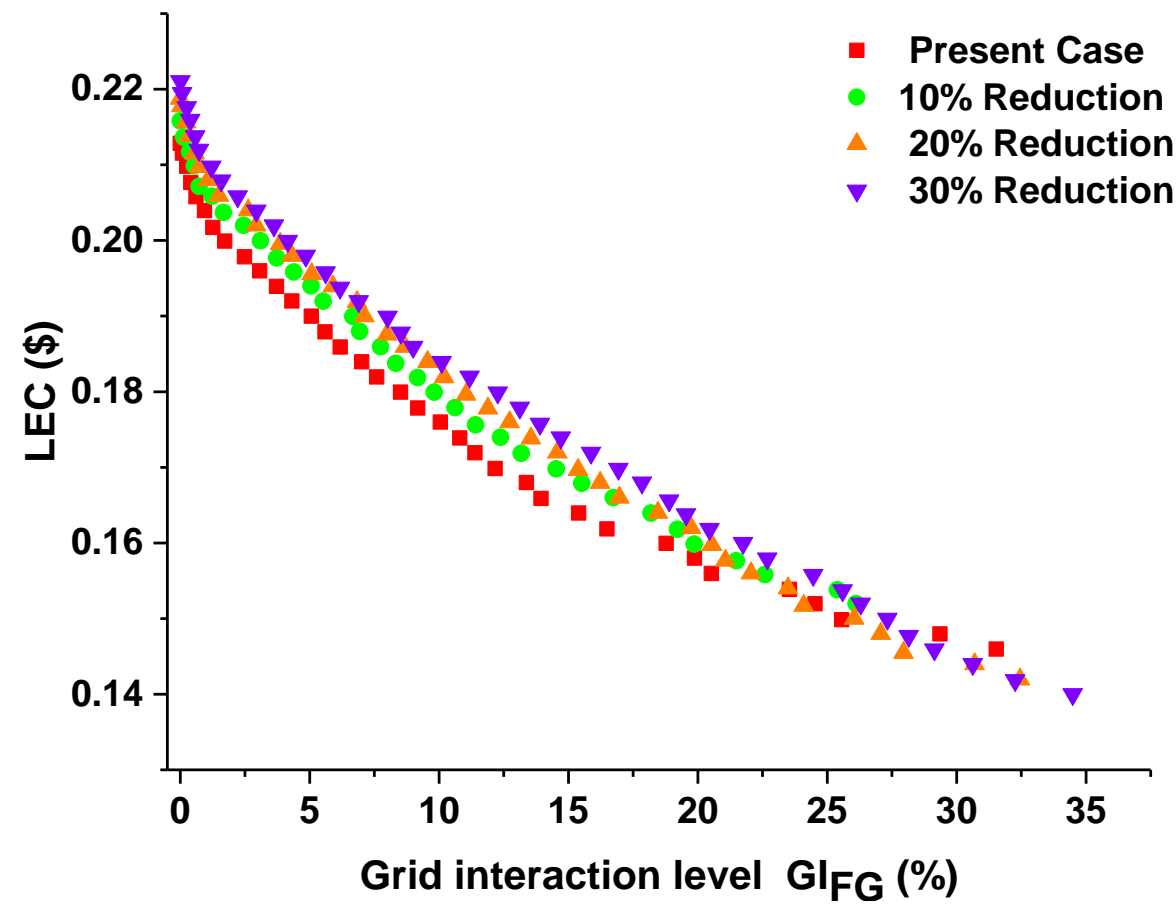

Fig. 14: Sensitivity analysis of market prices of the cost of energy in the grid on the LEC-GI IG Pareto front

\section{Conclusions}

This focuses on evaluating the potential of electrical hubs in integrating non-dispatchable renewable energy technologies such as SPV panels and wind turbines with minimum impact to grid. A novel optimization al gorithm in introduced with the support of a bi-level dispatch strategy to optimize electrical hubs considering both real time price and curtailments for import and export in the grid. A gray model based on fuzzy logic is introduced to control the operation of ICG in the primary algorithm while finite automata theory is used to in the secondary algorithm to control the energy interactions with grid and battery bank. Finally, multi objective optimization is conducted considering LEC and grid integration level.

The results obtained from the Pareto analysis shows that electrical hub can help to increase the share of wind and SPV generation beyond $60 \%$ of the annual demand of the electrical hub. From an economic perspective, the 
assessment of the energy system shows that limitations for purchasing electricity from the grid are more critical than selling: this is promising when one considers the present grid architecture. Furthermore, larger grid interaction curtailments increase the LEC of the system and hinder the integration of renewable energy sources to the grid. The LEC-GI $I_{\mathrm{IG}}$ Pareto front indicates that electrical hubs can actively participate to the energy market by generating quantities of electricity far larger than the demand of the electrical hub. However, an autonomous operation of

641 electrical hubs is not encouraged, as it notably increases the electrical power generation by the ICG minimizing the 642 SPV and wind integration. In conclusion, it can be stated that electrical hub is effective in increasing the nondispatchable renewable energy share with minimum impact to the grid when considering present Sri Lankan context.

644 Nonetheless, limitations in the initial capital investment need also to be addressed in this prospect, especially for 645 developing countries like Sri Lanka, which is a real challenge for solar and wind energy.

\section{$646 \quad$ Nomenclature}

\section{Sets:}

$\mathrm{t} \epsilon \mathrm{T}$ :set of all hours in the year

$\mathrm{F} \epsilon \mathrm{F}$ : set of objective functions

$\mathrm{N} \epsilon \mathrm{N}$ : set of decision space variables related to system design

$\mathrm{d} \epsilon \mathrm{D}$ : set of decision space variables related to control system (D : W U L)

$\mathrm{w} \in \mathrm{W}$ : set of decision space variable related to fuzzy controller $(W \subset D)$

$1 \epsilon \mathrm{L}$ : set of all decision space variables related to secondary level controller (LCD)

$\mathrm{S} \in \mathrm{S}$ : set of system components

\section{Decision space variable:}

\section{$N^{S P V} \quad$ Number of SPV Panels}

$\mathrm{N}^{\text {TY-SPV }}$ Type of SPV Panel

$N^{W} \quad$ Number of wind turbines

$\mathrm{N}^{\mathrm{TY}-\mathrm{W}}$ Type of wind turbine
$\mathrm{N}^{\text {Bat }} \quad$ Number of battery banks

k Type of ICG

$\mathrm{w}_{\mathrm{ij}} \quad$ weight matrix for fuzzy rules

$\operatorname{Lim}_{\mathrm{BC}} \quad$ limit cost for battery charge

$\operatorname{Lim}_{\mathrm{BD}}$ limit cost for battery discharge

$\operatorname{Lim}_{\text {GTB }}$ limit cost for battery charge from grid

$\operatorname{Lim}_{\mathrm{BTG}}$ limit cost for battery discharge to grid

$\mathrm{SOC}_{\min }$ minimum state of charge

$\mathrm{SOC}_{\mathrm{Min}, \mathrm{G}}$ minimum state of charge when discharging

to grid

$\mathrm{SOC}_{\text {Set }}$ maximum state of charged to be reached

when charging from grid

Other variables used in the model:

CRF Capital Recovery Factor

DOD Depth of Discharge 
FAC Fixed Annual Cash-flow

FACGI cash flow for grid integration

ICC Initial Capital Cost

$\theta_{t}^{S P V} \quad$ SPV cell temperature

$\eta_{t}^{P V} \quad$ Efficiency of SPV panels

$F_{t}^{I C G} \quad$ Fuel consumption by ICG

$G_{t}^{\beta} \quad$ Global tilted solar irradiation on SPV panel

$L P S_{t} \quad$ Loss of power supply

$P_{t}^{\text {Bat-Max }}$ maximum power flow from the battery

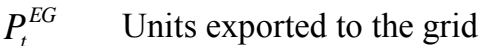

$P_{t}^{E L D} \quad$ Electricity demand of the micro grid at time step $\mathrm{t}$

$P_{t}^{I C G} \quad$ Power generation by ICG

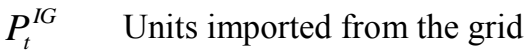

$P_{t}^{R E} \quad$ Power generated using renewables

$P_{t}^{S P V} \quad$ Power generated from SPV panels

$P_{t}^{W} \quad$ Power generated from wind turbines

$\mathrm{x}_{\mathrm{t}}^{\mathrm{k}} \quad$ Inputs to the fuzzy controller

$y_{t} \quad$ Operating load factor of ICG

$\mathrm{R}^{\mathrm{l}} \quad \mathrm{l}^{\text {th }}$ implication rule for the fuzzy controller

Input Parameters for the model:

$\beta \quad$ tilt angel of SPV panels

$\eta_{\mathrm{W}-\mathrm{losses}}$ General power losses in wind turbine

AM Air Mass

ASPV collector area of one SPV panel

ELD $_{\mathrm{t}} \quad$ Electricity Load Demand
$G C_{t}^{E G} \quad \mathrm{COE}$ for selling electricity to $\mathrm{MUG}$

$G C_{t}^{I G} \quad$ COE for purchasing electricity from MUG

$\mathrm{P}_{\mathrm{R}} \quad$ Rated power of the turbine

$\mathrm{v}_{\mathrm{CI}} \quad$ Cut-in wind speed of the turbine

$\mathrm{v}_{\mathrm{CO}} \quad$ Cut-off wind speed of the turbine

$v_{R} \quad$ Rated wind speed of the turbine

$v_{t} \quad$ Wind speed at hub level of wind turbine

\section{Objective functions used:}
LEC Levelized Energy Cost
$\mathrm{GI}_{\mathrm{EG}} \quad$ Grid Integration level considering exports
$\mathrm{GI}_{\mathrm{IG}} \quad$ Grid Integration level considering imports
$\mathrm{GI}_{\text {IEG }}$ Grid Integration level considering both imports and exports

\section{Constraints used:}

$\mathrm{EG}_{\text {Lim }}$ Maximal units sold to the grid

$\mathrm{IG}_{\mathrm{Lim}}$ maximum units purchased from the grid

LOLP Loss of Load Probability

\section{Other acronyms used}

ESP Energy Service Provider

GI Grid Interactions

ICG Internal Combustion Generator

SPV Solar PV

SOC State of charge of battery bank

t time step

OM Operation and maintenance cost

WRE Waste of Renewable Energy

GC Grid Cost for electricity 


\section{References}

[1] J. Blazejczak, F. G. Braun, D. Edler, and W.-P. Schill, "Economic effects of renewable energy expansion: A model-based analysis for Germany," Renew. Sustain. Energy Rev., vol. 40, pp. 1070-1080, Dec. 2014.

[2] B. Zakeri, S. Syri, and S. Rinne, "Higher renewable energy integration into the existing energy system of Finland - Is there any maximum limit?," Energy.

[3] E. Voumvoulakis, G. Asimakopoulou, S. Danchev, G. Maniatis, and A. Tsakanikas, "Large scale integration of intermittent renewable energy sources in the Greek power sector," Energy Policy, vol. 50, pp. 161-173, Nov. 2012.

[4] E. E. Sfikas, Y. A. Katsigiannis, and P. S. Georgilakis, "Simultaneous capacity optimization of distributed generation and storage in medium voltage microgrids," Int. J. Electr. Power Energy Syst., vol. 67, pp. 101113, May 2015.

[5] B. Ćosić, G. Krajačić, and N. Duić, "A 100\% renewable energy system in the year 2050: The case of Macedonia,” Energy, vol. 48, no. 1, pp. 80-87, Dec. 2012.

[6] D. Connolly, H. Lund, B. V. Mathiesen, and M. Leahy, "The first step towards a $100 \%$ renewable energysystem for Ireland," Appl. Energy, vol. 88, no. 2, pp. 502-507, Feb. 2011.

[7] B. V. Mathiesen, H. Lund, and K. Karlsson, " $100 \%$ Renewable energy systems, climate mitigation and economic growth," Appl. Energy, vol. 88, no. 2, pp. 488-501, Feb. 2011.

[8] H. Lund and B. V. Mathiesen, "Energy system analysis of $100 \%$ renewable energy systems - The case of Denmark in years 2030 and 2050," Energy, vol. 34, no. 5, pp. 524-531, May 2009.

[9] G. Xydis, "Comparison study between a Renewable Energy Supply System and a supergrid for achieving $100 \%$ from renewable energy sources in Islands," Int. J. Electr. Power Energy Syst., vol. 46, pp. 198-210, Mar. 2013.

[10] G. Sansavini, R. Piccinelli, L. R. Golea, and E. Zio, "A stochastic framework for uncertainty analysis in electric power transmission systems with wind generation," Renew. Energy, vol. 64, pp. 71-81, Apr. 2014.

[11] A. S. Brouwer, M. van den Broek, A. Seebregts, and A. Faaij, "Impacts of large-scale Intermittent Renewable Energy Sources on electricity systems, and how these can be modeled," Renew. Sustain. Energy Rev., vol. 33, pp. 443-466, May 2014.

[12] O. Hafez and K. Bhattacharya, "Optimal planning and design of a renewable energy based supply system for microgrids," Renew. Energy, vol. 45, pp. 7-15, Sep. 2012.

[13] F. F. Yanine and E. E. Sauma, "Review of grid-tie micro-generation systems without energy storage: Towards a new approach to sustainable hybrid energy systems linked to energy efficiency," Renew. Sustain. Energy Rev., vol. 26, pp. 60-95, Oct. 2013.

[14] A. T. D. Perera, R. A. Attalage, K. K. C. K. Perera, and V. P. C. Dassanayake, "Converting existing Internal Combustion Generator (ICG) systems into HESs in standalone applications," Energy Convers. Manag., vol. 74, pp. 237-248, Oct. 2013.

[15] A. H. Fathima and K. Palanisamy, "Optimization in microgrids with hybrid energy systems - A review," Renew. Sustain. Energy Rev., vol. 45, pp. 431-446, May 2015.

[16] R. Dufo-López et al., "Multi-objective optimization minimizing cost and life cycle emissions of stand-alone PV-wind-diesel systems with batteries storage," Appl. Energy, vol. 88, no. 11, pp. 4033-4041, Nov. 2011.

[17] A. T. D. Perera, R. A. Attalage, K. K. C. K. Perera, and V. P. C. Dassanayake, "Designing standalone hybrid energy systems minimizing initial investment, life cycle cost and pollutant emission," Energy, vol. 54, pp. 220-230, Jun. 2013.

[18] I. R. Cristóbal-Monreal and R. Dufo-López, "Optimisation of photovoltaic-diesel-battery stand-alone systems minimising system weight," Energy Convers. Manag., vol. 119, pp. 279-288, Jul. 2016.

[19] M. Bortolini, M. Gamberi, A. Graziani, and F. Pilati, "Economic and environmental bi-objective design of an off-grid photovoltaic-battery-diesel generator hybrid energy system," Energy Convers. Manag., vol. 106, pp. 1024-1038, Dec. 2015.

[20] C. Weber, F. Maréchal, D. Favrat, and S. Kraines, "Optimization of an SOFC-based decentralized polygeneration system for providing energy services in an office-building in Tōkyō," Appl. Therm. Eng., vol. 26, no. 13, pp. 1409-1419, Sep. 2006.

[21] S. Fazlollahi, G. Becker, A. Ashouri, and F. Maréchal, "Multi-objective, multi-period optimization of district energy systems: IV - A case study," Energy, vol. 84, pp. 365-381, May 2015.

[22] R. Evins, "Multi-level optimization of building design, energy system sizing and operation," Energy.

[23] A. Maroufmashat et al., "Modeling and optimization of a network of energy hubs to improve economic and emission considerations," Energy, vol. 93, Part 2, pp. 2546-2558, Dec. 2015. 
[24] K. A. Pruitt, S. Leyffer, A. M. Newman, and R. J. Braun, "A mixed-integer nonlinear program for the optimal design and dispatch of distributed generation systems," Optim. Eng., vol. 15, no. 1, pp. 167-197, Aug. 2013.

[25] A. Piacentino and F. Cardona, "EABOT - Energetic analysis as a basis for robust optimization of trigeneration systems by linear programming," Energy Convers. Manag., vol. 49, no. 11, pp. 3006-3016, Nov. 2008.

[26] K. A. Pruitt, R. J. Braun, and A. M. Newman, "Evaluating shortfalls in mixed-integer programming approaches for the optimal design and dispatch of distributed generation systems," Appl. Energy, vol. 102, pp. 386-398, Feb. 2013.

[27] R. Evins, K. Orehounig, V. Dorer, and J. Carmeliet, "New formulations of the 'energy hub' model to address operational constraints," Energy, vol. 73, pp. 387-398, Aug. 2014.

[28] K. Orehounig, R. Evins, and V. Dorer, "Integration of decentralized energy systems in neighbourhoods using the energy hub approach," Appl. Energy, vol. 154, pp. 277-289, Sep. 2015.

[29] M. Moeini-Aghtaie, A. Abbaspour, M. Fotuhi-Firuzabad, and P. Dehghanian, "Optimized Probabilistic PHEVs Demand Management in the Context of Energy Hubs," IEEE Trans. Power Deliv., vol. 30, no. 2, pp. 996-1006, Apr. 2015.

[30] M. Moeini-Aghtaie, P. Dehghanian, M. Fotuhi-Firuzabad, and A. Abbaspour, "Multiagent Genetic Algorithm: An Online Probabilistic View on Economic Dispatch of Energy Hubs Constrained by Wind Availability," IEEE Trans. Sustain. Energy, vol. 5, no. 2, pp. 699-708, Apr. 2014.

[31] M. Rastegar, M. Fotuhi-Firuzabad, H. Zareipour, and M. Moeini-Aghtaie, "A Probabilistic Energy Management Scheme for Renewable-Based Residential Energy Hubs," IEEE Trans. Smart Grid, vol. PP, no. 99, pp. 1-11, 2016.

[32] A. Maleki, F. Pourfayaz, and M. A. Rosen, "A novel framework for optimal design of hybrid renewable energy-based autonomous energy systems: A case study for Namin, Iran," Energy, vol. 98, pp. 168-180, Mar. 2016.

[33] A. S. O. Ogunjuyigbe, T. R. Ayodele, and O. A. Akinola, "Optimal allocation and sizing of PV/Wind/Splitdiesel/Battery hybrid energy system for minimizing life cycle cost, carbon emission and dump energy of remote residential building," Appl. Energy, vol. 171, pp. 153-171, Jun. 2016.

[34] S. R. Tito, T. T. Lie, and T. N. Anderson, "Optimal sizing of a wind-photovoltaic-battery hybrid renewable energy system considering socio-demographic factors," Sol. Energy, vol. 136, pp. 525-532, Oct. 2016.

[35] Z. Shi, R. Wang, and T. Zhang, "Multi-objective optimal design of hybrid renewable energy systems using preference-inspired coevolutionary approach,” Sol. Energy, vol. 118, pp. 96-106, Aug. 2015.

[36] A. T. D. Perera, R. A. Attalage, K. K. C. K. Perera, and V. P. C. Dassanayake, "A hybrid tool to combine multi-objective optimization and multi-criterion decision making in designing standalone hybrid energy systems," Appl. Energy, vol. 107, pp. 412-425, Jul. 2013.

[37] O. Erdinc and M. Uzunoglu, "Optimum design of hybrid renewable energy systems: Overview of different approaches,” Renew. Sustain. Energy Rev., vol. 16, no. 3, pp. 1412-1425, Apr. 2012.

[38] A. T. D. Perera, R. A. Attalage, and K. K. C. K. Perera, "Optimal design of a grid connected hybrid electrical energy system using evolutionary computation," in 2013 8th IEEE International Conference on Industrial and Information Systems (ICIIS), 2013, pp. 12-17.

[39] A. M. Eltamaly, M. A. Mohamed, and A. I. Alolah, "A novel smart grid theory for optimal sizing of hybrid renewable energy systems," Sol. Energy, vol. 124, pp. 26-38, Feb. 2016.

[40] J. L. Bernal-Agustín and R. Dufo-López, "Hourly energy management for grid-connected wind-hydrogen systems," Int. J. Hydrog. Energy, vol. 33, no. 22, pp. 6401-6413, Nov. 2008.

[41] R. Dufo-López, "Optimisation of size and control of grid-connected storage under real time electricity pricing conditions," Appl. Energy, vol. 140, pp. 395-408, Feb. 2015.

[42] A. Rezvani, A. Khalili, A. Mazareie, and M. Gandomkar, "Modeling, control, and simulation of grid connected intelligent hybrid battery/photovoltaic system using new hybrid fuzzy-neural method," ISA Trans.

[43] S. Safari, M. M. Ardehali, and M. J. Sirizi, "Particle swarm optimization based fuzzy logic controller for autonomous green power energy system with hydrogen storage," Energy Convers. Manag., vol. 65, pp. 4149, Jan. 2013.

[44] S. Berrazouane and K. Mohammedi, "Parameter optimization via cuckoo optimization algorithm of fuzzy controller for energy management of a hybrid power system," Energy Convers. Manag., vol. 78, pp. 652-660, Feb. 2014.

[45] M. H. Athari and M. M. Ardehali, "Operational performance of energy storage as function of electricity prices for on-grid hybrid renewable energy system by optimized fuzzy logic controller," Renew. Energy, vol. 85, pp. 890-902, Jan. 2016. 
[46] L. Olatomiwa, S. Mekhilef, M. S. Ismail, and M. Moghavvemi, "Energy management strategies in hybrid renewable energy systems: A review," Renew. Sustain. Energy Rev., vol. 62, pp. 821-835, Sep. 2016.

[47] G. Krajačić, N. Duić, Z. Zmijarević, B. V. Mathiesen, A. A. Vučinić, and M. da Graça Carvalho, "Planning for a $100 \%$ independent energy system based on smart energy storage for integration of renewables and CO2 emissions reduction," Appl. Therm. Eng., vol. 31, no. 13, pp. 2073-2083, Sep. 2011.

[48] J. Salom, A. J. Marszal, J. Widén, J. Candanedo, and K. B. Lindberg, "Analysis of load match and grid interaction indicators in net zero energy buildings with simulated and monitored data," Appl. Energy, vol. 136, pp. 119-131, Dec. 2014.

[49] F. Ueckerdt et al., "Representing power sector variability and the integration of variable renewables in longterm energy-economy models using residual load duration curves," Energy, vol. 90, Part 2, pp. 1799-1814, Oct. 2015.

[50] "EnergyPlus | EnergyPlus." [Online]. Available: https://energyplus.net/. [Accessed: 25-Nov-2015].

[51] "CitySim Software | LESO-PB.” [Online]. Available: http://citysim.epfl.ch/. [Accessed: 25-Nov-2015].

[52] S. Fazlollahi, G. Becker, and F. Maréchal, "Multi-objectives, multi-period optimization of district energy systems: III. Distribution networks," Comput. Chem. Eng., vol. 66, pp. 82-97, Jul. 2014.

[53] J. Soares, M. A. Fotouhi Ghazvini, Z. Vale, and P. B. de Moura Oliveira, "A multi-objective model for the day-ahead energy resource scheduling of a smart grid with high penetration of sensitive loads," Appl. Energy, vol. 162, pp. 1074-1088, Jan. 2016.

[54] W. Tushar et al., "Three-Party Energy Management With Distributed Energy Resources in Smart Grid," IEEE Trans. Ind. Electron., vol. 62, no. 4, pp. 2487-2498, Apr. 2015.

[55] A. Safdarian, M. Fotuhi-Firuzabad, M. Lehtonen, and F. Aminifar, "Optimal Electricity Procurement in Smart Grids With Autonomous Distributed Energy Resources," IEEE Trans. Smart Grid, vol. 6, no. 6, pp. 29752984, Nov. 2015.

[56] A. T. D. Perera, D. M. I. J. Wickremasinghe, D. V. S. Mahindarathna, R. A. Attalage, K. K. C. K. Perera, and E. M. Bartholameuz, "Sensitivity of internal combustion generator capacity in standalone hybrid energy systems," Energy, vol. 39, no. 1, pp. 403-411, Mar. 2012.

[57] G. Notton, V. Lazarov, and L. Stoyanov, "Optimal sizing of a grid-connected PV system for various PV module technologies and inclinations, inverter efficiency characteristics and locations," Renew. Energy, vol. 35, no. 2, pp. 541-554, Feb. 2010.

[58] V. Thapar, G. Agnihotri, and V. K. Sethi, "Critical analysis of methods for mathematical modelling of wind turbines," Renew. Energy, vol. 36, no. 11, pp. 3166-3177, Nov. 2011.

[59] F. O. Hocaoğlu, Ö. N. Gerek, and M. Kurban, "A novel hybrid (wind-photovoltaic) system sizing procedure," Sol. Energy, vol. 83, no. 11, pp. 2019-2028, Nov. 2009.

[60] S. Diaf, D. Diaf, M. Belhamel, M. Haddadi, and A. Louche, "A methodology for optimal sizing of autonomous hybrid PV/wind system," Energy Policy, vol. 35, no. 11, pp. 5708-5718, Nov. 2007.

[61] M. K. Deshmukh and S. S. Deshmukh, "Modeling of hybrid renewable energy systems," Renew. Sustain. Energy Rev., vol. 12, no. 1, pp. 235-249, Jan. 2008.

[62] R. Dufo-López and J. L. Bernal-Agustín, "Design and control strategies of PV-Diesel systems using genetic algorithms," Sol. Energy, vol. 79, no. 1, pp. 33-46, Jul. 2005.

[63] S. D. Downing and D. F. Socie, "Simple rainflow counting algorithms," Int. J. Fatigue, vol. 4, no. 1, pp. 3140, Jan. 1982.

[64] E. Zio and T. Aven, "Uncertainties in smart grids behavior and modeling: What are the risks and vulnerabilities? How to analyze them?," Energy Policy, vol. 39, no. 10, pp. 6308-6320, Oct. 2011.

[65] B. Verbruggen and J. Driesen, "Grid Impact Indicators for Active Building Simulations," IEEE Trans. Sustain. Energy, vol. 6, no. 1, pp. 43-50, Jan. 2015.

[66] A. N. Celik, "Effect of different load profiles on the loss-of-load probability of stand-alone photovoltaic systems," Renew. Energy, vol. 32, no. 12, pp. 2096-2115, Oct. 2007.

[67] D. Abbes, A. Martinez, and G. Champenois, "Life cycle cost, embodied energy and loss of power supply probability for the optimal design of hybrid power systems," Math. Comput. Simul., vol. 98, pp. 46-62, Apr. 2014.

[68] A. Hadj Arab, F. Chenlo, and M. Benghanem, "Loss-of-load probability of photovoltaic water pumping systems," Sol. Energy, vol. 76, no. 6, pp. 713-723, 2004.

[69] A. Heydari and A. Askarzadeh, "Optimization of a biomass-based photovoltaic power plant for an off-grid application subject to loss of power supply probability concept," Appl. Energy, vol. 165, pp. 601-611, Mar. 2016. 
[70] A. T. D. Perera, A. N. Madusanka, R. A. Attalage, and K. K. C. K. Perera, "A multi criterion analysis for renewable energy integration process of a standalone hybrid energy system with internal combustion generator," J. Renew. Sustain. Energy, vol. 7, no. 4, p. 043128, Jul. 2015.

[71] T. Takagi and M. Sugeno, "Fuzzy identification of systems and its applications to modeling and control," IEEE Trans. Syst. Man Cybern., vol. SMC-15, no. 1, pp. 116-132, Jan. 1985.

[72] M. Sugeno, "An introductory survey of fuzzy control," Inf. Sci., vol. 36, no. 1, pp. 59-83, Jul. 1985.

[73] M. Sugeno and G. T. Kang, "Structure identification of fuzzy model," Fuzzy Sets Syst., vol. 28, no. 1, pp. 1533, Oct. 1988.

[74] C.-Y. Li and G.-P. Liu, "Optimal fuzzy power control and management of fuel cell/battery hybrid vehicles," J. Power Sources, vol. 192, no. 2, pp. 525-533, Jul. 2009.

[75] X. Li, L. Xu, J. Hua, X. Lin, J. Li, and M. Ouyang, "Power management strategy for vehicular-applied hybrid fuel cell/battery power system," J. Power Sources, vol. 191, no. 2, pp. 542-549, Jun. 2009.

[76] S. Caux, W. Hankache, M. Fadel, and D. Hissel, "On-line fuzzy energy management for hybrid fuel cell systems," Int. J. Hydrog. Energy, vol. 35, no. 5, pp. 2134-2143, Mar. 2010.

[77] J. Solano Martínez, R. I. John, D. Hissel, and M.-C. Péra, "A survey-based type-2 fuzzy logic system for energy management in hybrid electrical vehicles," Inf. Sci., vol. 190, pp. 192-207, May 2012.

[78] P. Wong et al., "The IEEE Reliability Test System-1996. A report prepared by the Reliability Test System Task Force of the Application of Probability Methods Subcommittee," IEEE Trans. Power Syst., vol. 14, no. 3, pp. 1010-1020, Aug. 1999.

[79] Z. Iverson, A. Achuthan, P. Marzocca, and D. Aidun, "Optimal design of hybrid renewable energy systems (HRES) using hydrogen storage technology for data center applications," Renew. Energy, vol. 52, pp. 79-87, Apr. 2013.

[80] S. Upadhyay and M. P. Sharma, "A review on configurations, control and sizing methodologies of hybrid energy systems," Renew. Sustain. Energy Rev., vol. 38, pp. 47-63, Oct. 2014.

[81] S. Sanajaoba and E. Fernandez, "Maiden application of Cuckoo Search algorithm for optimal sizing of a remote hybrid renewable energy System," Renew. Energy, vol. 96, Part A, pp. 1-10, Oct. 2016.

[82] J. L. Bernal-Agustín and R. Dufo-López, "Efficient design of hybrid renewable energy systems using evolutionary algorithms," Energy Convers. Manag., vol. 50, no. 3, pp. 479-489, Mar. 2009.

[83] S. Bahramara, M. P. Moghaddam, and M. R. Haghifam, "Optimal planning of hybrid renewable energy systems using HOMER: A review,” Renew. Sustain. Energy Rev., vol. 62, pp. 609-620, Sep. 2016.

[84] M. Fadaee and M. A. M. Radzi, "Multi-objective optimization of a stand-alone hybrid renewable energy system by using evolutionary algorithms: A review," Renew. Sustain. Energy Rev., vol. 16, no. 5, pp. 33643369, Jun. 2012.

[85] K. Deb, M. Mohan, and S. Mishra, "Evaluating the $\varepsilon$-Domination Based Multi-Objective Evolutionary Algorithm for a Quick Computation of Pareto-Optimal Solutions," Evol Comput, vol. 13, no. 4, pp. 501-525, Dec. 2005.

[86] M. Laumanns, L. Thiele, K. Deb, and E. Zitzler, "Combining Convergence and Diversity in Evolutionary Multiobjective Optimization," Evol. Comput., vol. 10, no. 3, pp. 263-282, Sep. 2002.

[87] K. Deb, "An efficient constraint handling method for genetic algorithms," Comput. Methods Appl. Mech. Eng., vol. 186, no. 2-4, pp. 311-338, Jun. 2000.

[88] K. Deb and H.-G. Beyer, "Self-Adaptive Genetic Algorithms with Simulated Binary Crossover," Evol. Comput., vol. 9, no. 2, pp. 197-221, Jun. 2001.

[89] A. K. Qin, V. L. Huang, and P. N. Suganthan, "Differential Evolution Algorithm With Strategy Adaptation for Global Numerical Optimization," IEEE Trans. Evol. Comput., vol. 13, no. 2, pp. 398-417, Apr. 2009.

[90] R. Storn and K. Price, "Differential Evolution - A Simple and Efficient Heuristic for global Optimization over Continuous Spaces," J. Glob. Optim., vol. 11, no. 4, pp. 341-359.

[91] J. Brest, S. Greiner, B. Boskovic, M. Mernik, and V. Zumer, "Self-Adapting Control Parameters in Differential Evolution: A Comparative Study on Numerical Benchmark Problems," IEEE Trans. Evol. Comput., vol. 10, no. 6, pp. 646-657, Dec. 2006.

[92] A. Konak, D. W. Coit, and A. E. Smith, "Multi-objective optimization using genetic algorithms: A tutorial," Reliab. Eng. Syst. Saf., vol. 91, no. 9, pp. 992-1007, Sep. 2006. 